\title{
Tidal asymmetry in estuaries with mixed semidiurnal/diurnal tides
}

\author{
Nicholas J. Nidzieko ${ }^{1,2}$ \\ Received 9 October 2009; revised 17 February 2010; accepted 12 March 2010; published 5 August 2010.
}

[1] Tidal asymmetry in estuaries with mixed, mainly semidiurnal tides arises from both the interaction of principal tides and the higher harmonics generated by distortions within the estuary. The duration asymmetry in rise and fall of water level caused by principal tides on the west coast of the continental United States is ebb-dominant, and so the tide entering estuaries is also ebb-dominant, prior to any internal distortions within the estuary. The interaction of higher harmonics with principal constituents either augments or cancels the duration asymmetry in the principal tides. In estuaries where tidal elevation and velocity phase are near quadrature $\left(90^{\circ}\right.$ out of phase), the duration asymmetry in tidal elevation leads to asymmetries in tidal current magnitude. Asymmetry can be conveniently quantified in terms of the sample skewness, $\gamma_{1}$, the normalized third sample moment about the mean. An analytic approximation to the skewness shows that traditional metrics of asymmetry, namely the ratio of constituent amplitudes and the relative constituent phase difference, arise from calculating the third sample moment. Observations from three California estuaries of different morphologies are presented as an illustration of how skewness can be used to quantify asymmetry in real systems. As in semidiurnal systems, morphology is a good predictor of whether higher harmonics engender ebb-dominance or flood-dominance, however asymmetry imposed by principal tides at the mouth must first be overcome and so there is a spatial evolution in the total asymmetry. Quantifying observations via skewness should be considered in addition to traditional metrics in estuaries with mixed tides.

Citation: Nidzieko, N. J. (2010), Tidal asymmetry in estuaries with mixed semidiurnal/diurnal tides, J. Geophys. Res., 115, C08006, doi:10.1029/2009JC005864.

\section{Introduction}

[2] Tidal asymmetry occurs when the combination of multiple tidal constituents produces a tide with discrepancies in the rise- and fall-duration of water elevation; this duration asymmetry may be manifest as an inequality in flood/ebb tidal current magnitudes [Boon and Byrne, 1981] when tidal elevation and velocity are near quadrature. Phase difference between constituents dictates the direction of asymmetry (i.e., flood- or ebb-dominance), while the ratio of constituent amplitudes reflects the degree of distortion [Friedrichs and Aubrey, 1988]. In frictionally-dominated estuaries with semidiurnal tides (form number $F=\left(a_{\mathrm{K}_{1}}+a_{\mathrm{O}_{1}}\right) /\left(a_{\mathrm{M}_{2}}+a_{\mathrm{S}_{2}}\right)<0.25$, where $a_{n}$ is tidal constituent amplitude [National Ocean Service, 2000]) the primary source of asymmetry is the interaction of the principal lunar semidiurnal tide $\mathrm{M}_{2}$ with its first overtide, the lunar quarter diurnal $\mathrm{M}_{4}$ [Speer and Aubrey, 1985; van de Kreeke and Robaczemska, 1993]. Overtides (harmonic frequencies that are integer multiples of a prin-

\footnotetext{
${ }^{1}$ Environmental Fluid Mechanics Laboratory, Stanford University, Stanford, California, USA.

${ }^{2}$ Now at Applied Ocean Physics and Engineering Department, Woods Hole Oceanographic Institution, Woods Hole, Massachusetts, USA.

Copyright 2010 by the American Geophysical Union. 0148-0227/10/2009JC005864
}

cipal constituent frequency) and compound tides (harmonics created from sums or differences of two frequencies) arise primarily from distortion of astronomical tides in shallow water. The physical mechanisms responsible for this distortion are represented by nonlinearities in the equations of motion: time-varying depth and embayment width in the continuity equation; and quadratic friction, time-varying depth in the friction term, and advective acceleration in the momentum equation [Parker, 1991]. Most tidal asymmetry literature has examined semidiurnal systems on the U.S. east coast [Aubrey and Speer, 1985; Friedrichs and Aubrey, 1988, 1994; Blanton et al., 2002] and in western Europe [Dronkers, 1986; Lanzoni and Seminara, 1998; Wang et al., 1999; Savenije and Veling, 2005]; consequently, these papers focus almost exclusively on the interaction between $\mathrm{M}_{2}$ and $\mathrm{M}_{4}$ as the source of asymmetry.

[3] Asymmetrical tides are also produced through the interaction of diurnal and semidiurnal constituents in mixed, mainly semidiurnal tidal regimes $(0.25<F<1.5)$, primarily through the combination of the lunar $\left(\mathrm{K}_{1}\right)$ and lunisolar $\left(\mathrm{O}_{1}\right)$ diurnal tides with $\mathrm{M}_{2}$. The phase relationship between the diurnal and semidiurnal constituents dictates the direction of asymmetry by determining whether higher-high water (HHW) precedes or follows lower-low water (LLW). Friedrichs [1995] recognized that the tendency for HHW to precede LLW along the U.S. west coast resulted in a predominantly ebb- 
(a) tide stations

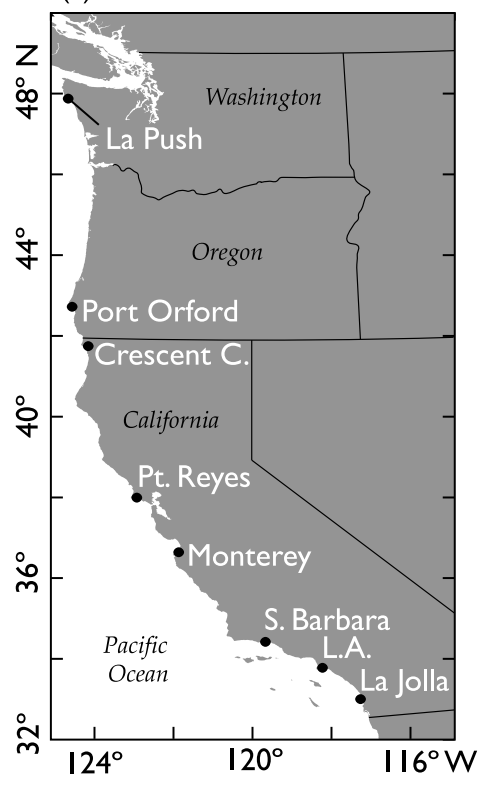

(b) amplitude

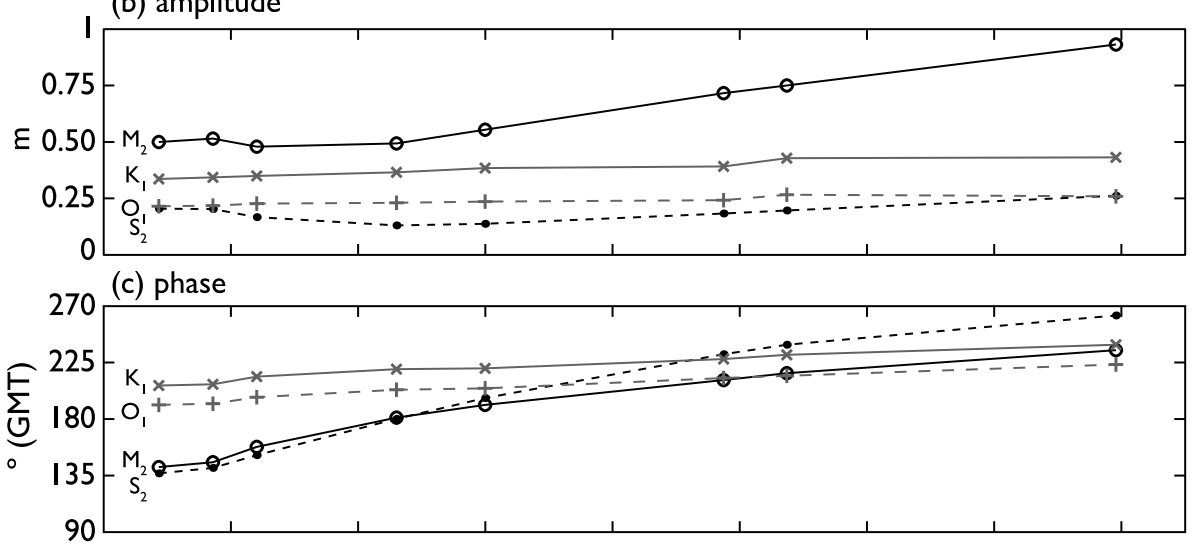

(d) skewness (duration asymmetry)

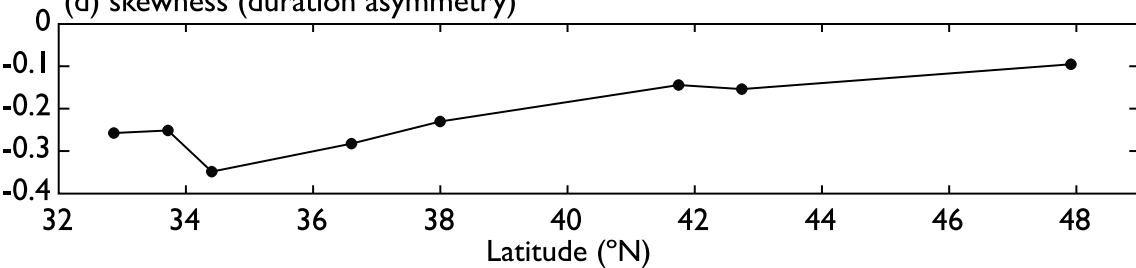

Figure 1. (a) NOAA National Ocean Service stations along the west coast. Only stations with no significant shallow water constituents are shown. (b) Amplitude and (c) phase, relative to Greenwich Mean Time, of tidal elevation for selected principal constituents. Not shown are the amplitudes of $\mathrm{P}_{1}$ and $\mathrm{N}_{2}$, which are each roughly $10 \mathrm{~cm}$ along the entire coast; the phases of $\mathrm{P}_{1}$ and $\mathrm{N}_{2}$ trend with the other diurnal and semidiurnal constituents, respectively. (d) Skewness (duration asymmetry) equation (10), of yearlong synthetic tidal records constructed of all harmonic constituents reported by NOS at each station. The NOS stations are, from north to south: 9442396 La Push, WA; 9431647 Port Orford, OR; 9419750 Crescent City, CA; 9415020 Point Reyes, CA; 9413450 Monterey, CA; 9411340 Santa Barbara, CA; 9410660 Los Angeles, CA; 9410230 La Jolla, CA.

dominant tidal regime, and speculated that this mixed tidal forcing contributed to systematic differences in channel morphology in U.S. west coast estuaries versus those along the Atlantic coasts of the U.S. and Europe. Recently, the interaction of this tidal triad was quantified by Hoitink et al. [2003] for tidal currents, and examined by Woodworth et al. [2005] for tidal elevation. Asymmetry in diurnal $(F>3)$ regimes has been examined by Ranasinghe and Pattiaratchi [2000]; they observed that principal tide phasing affected duration asymmetry and concluded that tidal inlet asymmetry was a direct consequence of oceanic forcing that varied with phase angle between constituents. The phasing between these principal constituents is not fixed within an estuary, as the response of $\mathrm{K}_{1}$ and $\mathrm{O}_{1}$ to quadratic friction differs in the presence of $\mathrm{M}_{2}$ [Godin and Martinez, 1994] and the celerity of each constituent is frequency-dependent [Godin, 1985]. Consequently, asymmetry in mixed, mainly semidiurnal estuaries is affected by both how the principal tides propagate as well as the nonlinear growth of higher harmonic constituents (overtides and compound tides) within the estuary.

[4] The purpose of this paper is to examine tidal asymmetry in estuaries with mixed, mainly semidiurnal tides in shallow estuaries typical of California. Along the continental shelf of the U.S. west coast, the phases of the diurnal and semidiurnal tidal constituents (Figure 1) result in a tide where HHW precedes LLW during spring tides (Figure 2).
Consequently, the tide entering an estuary along the west coast is ebb-dominant with respect to rise and fall duration, prior to any internal distortion within the estuary. Here I address two questions in the context of short, shallow estuaries. (1) How does asymmetry from principal constituents change with distance into the estuary? Each tidal constituent has a different celerity and so changes in the relative phasing between constituents within the estuary may alter asymmetry. (2) How does asymmetry from higher harmonics contribute to total asymmetry? I consider how the asymmetry created by nonlinear distortion of the tides augments or cancels asymmetry from principal tides. The discussion and analysis are cast in terms of duration asymmetries in the rise and fall of water elevation. As previously mentioned, when tidal elevation and velocity are in quadrature, asymmetry in tidal elevation generates asymmetries in velocity in the absence of confounding factors such as river discharge and local bathymetry.

[5] This paper is arranged as follows. In the next section, I briefly review the relevant physics of tides in short, shallow estuaries. The simple governing equation provides a convenient framework for examining tidal asymmetry from both principal tides and higher harmonics in section 3. I quantify asymmetry via the skewness of the sample observations, and show that traditional metrics of asymmetry are contained in the skewness. In section 4, the general analytic results are 
(a) Crescent City - 9419750

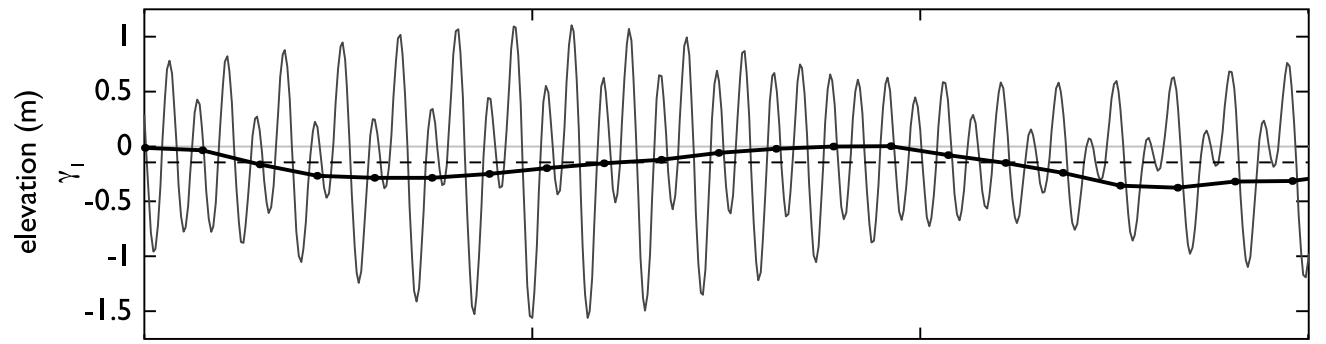

(b) La Jolla - 9410230

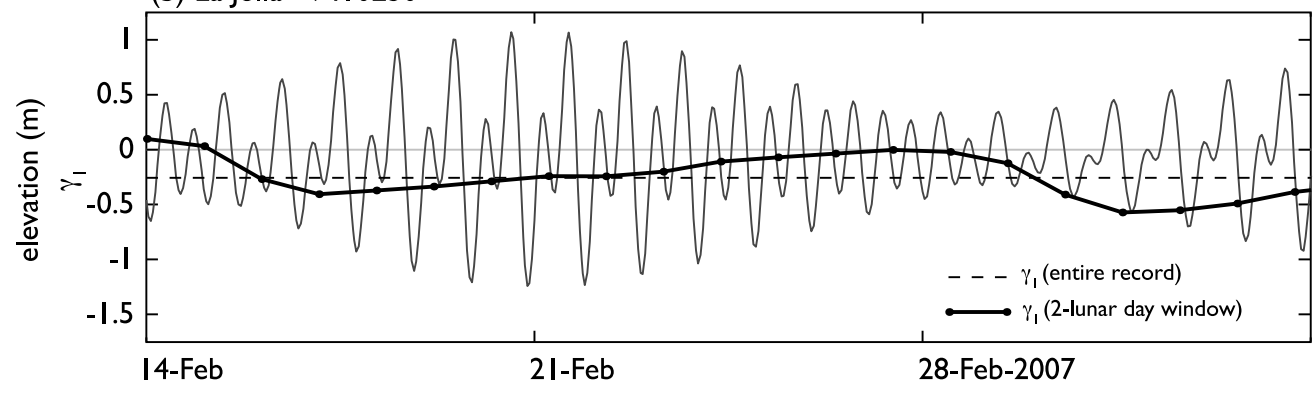

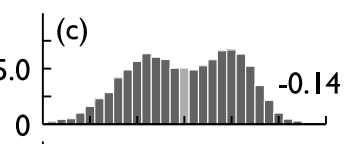

(d)
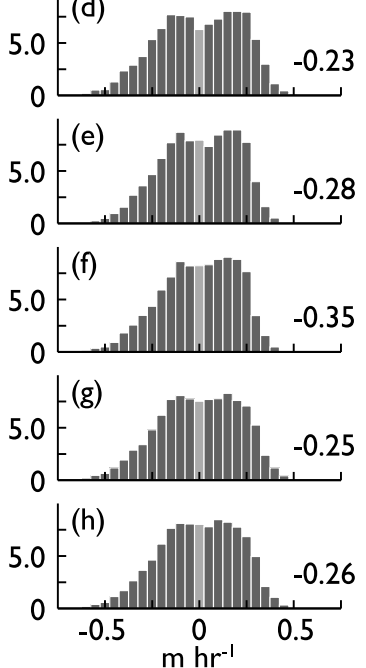

Figure 2. Examples of the duration asymmetry in the mixed, mainly semidiurnal tide along the U.S. west coast. The tidal records (gray line) are constructed using all constituents available for NOS stations at (a) Crescent City and (b) La Jolla. The solid dark line is the two-lunar day skewness computed with equation (10). The dashed line is the skewness of the full record for 2007. (c-h) Histograms of tidal elevation time derivative illustrate duration asymmetry, with the skewness of the full record indicated in numeral form. Figures $2 \mathrm{c}-2 \mathrm{~h}$ are the stations in Figure 1 from Crescent City to La Jolla, respectively.

discussed in the context of observations from three California estuaries: Tomales Bay, Elkhorn Slough, and Tijuana River Estuary.

\section{Tides in Shallow Estuaries}

[6] This paper is primarily concerned with the numerous smaller estuaries along the California coast, where the role of tidal asymmetry in net sediment transport [Dronkers, 1986] is important to inlet stability and long-term morphological change. These estuaries can be generalized (with the exception of San Francisco Bay) as being short and shallow; baroclinic dynamics are comparatively weak for most of the year due to the semi-arid Mediterranean climate [Largier et al., 1997], and so mean river flows are generally negligible. In this context, short refers to the length of the estuary $L$ relative to the tidal wavelength, while shallow implies that the amplitude of the tide is the same order as the tidal-mean depth $h(x)$ of the estuary. The width of the main channel below mean lower-low water (MLLW) is denoted by $B(x)$, while the total estuary width $b(x, t)-$ encompassing tidal flats and intertidal marsh up to mean higher high water (MHHW)-varies with the tidal sea surface elevation $\zeta(x, t)$. The total depth is $H(x, t)=h+\zeta$. The along-channel coordinate $x$ is positive up-estuary, with $x=0$ at the mouth; $t$ is time. Following previous studies of systems with similar channel-shoal morphologies [Speer and Aubrey, 1985; Friedrichs and Aubrey, 1988], along-channel momentum is conveyed only within the main channel through a cross-sectional area $A(x, t)=B H$, and friction from channel walls may be neglected for $B \gg h$.
[7] The observed tide $\zeta$ can be represented by the summation of $N$ individual constituents $\zeta_{n}$, generically of the form

$$
\zeta(x, t)=\sum_{n=1}^{N} \zeta_{n}=\sum_{n=1}^{N} a_{n} \cos \left(\omega_{n} t-k_{n} x-\phi_{n}\right),
$$

where $\omega=2 \pi / T$ is tidal frequency, $T$ is tidal period, $k$ is the wave number which reflects the cumulative delay in the waveform due to bathymetry and friction along the estuary, and $\phi$ is the phase at $x=0$ referenced to a common time coordinate. The observed phase $\varphi=k x+\phi$ of any constituent is the combined delay in the waveform and the time-coordinate reference, and the observed amplitude $a$ is one-half the range. The celerity, or wave speed, is $c=\omega / k$. The observed tidal current can be represented similarly by a summation of tidal harmonics with individual amplitudes, wave numbers, and reference phases.

[8] Given a time series of tidal elevation, least-squares harmonic analysis [Godin, 1991; Pawlowicz et al., 2002] can be used to find the constituent amplitude and phase, and the phase lag of any particular constituent between two observational points can be used to find the wave number. The triad $\mathrm{K}_{1}, \mathrm{O}_{1}$, and $\mathrm{M}_{2}$ produces the mixed, semidiurnal tide characteristic of the west coast; this is modulated by several constituents with amplitudes greater than $10 \mathrm{~cm}$ (Figure 1b): the solar semidiurnal constituent $\mathrm{S}_{2}$, the solar diurnal constituent $\mathrm{P}_{1}$, and the larger lunar elliptic semidiurnal $\mathrm{N}_{2}$. The slight differences in angular velocity within the diurnal and semidiurnal bands produce fortnightly (spring-neap) and seasonal modulations in tidal range. Within estuaries and shallow coastal seas, overtides and compound tides can be 
produced in both higher and lower frequency bands [Godin and Gonzalez, 1991]. The largest higher harmonics in estuaries along the west coast are $\mathrm{M}_{4}, \mathrm{MK}_{3}, \mathrm{MS}_{4}$, and $\mathrm{MO}_{3}$ [e.g., Dworak and Gomez-Valdes, 2005; Nidzieko, 2009]; here I focus primarily on $\mathrm{M}_{4}$ and $\mathrm{MK}_{3}$, as the response of constituents within the same band is generally similar [Aubrey and Speer, 1985].

[9] Although many detailed solutions for tidal response within an estuary have been developed [Prandle and Rahman, 1980; Jay, 1991; Prandle, 2003; Savenije et al., 2008], their notation is less amenable to interpretation, and I use the solutions of Friedrichs and Aubrey [1994, hereafter FA94] for a barotropic tide in a strongly convergent channel. One of the basic premises of the FA94 solutions, that the advancement of the tidal wave is a function of the channel convergence length scale $1 / L_{A} \approx-\frac{1}{A} \frac{\partial A}{\partial x}$, limits the application of these solutions to the portion of the channel more than $L_{A}$ away from the head of the estuary. Despite this limitation, the solutions of FA94 adequately represent the main features of these systems (finite wave speed, velocity and elevation near quadrature). As the main goal of this paper is to examine how the growth of nonlinearities might affect asymmetry generated by principal tides, the compact form and simple notation of the governing equation of FA94 facilitates examining the consequences of along-channel phase changes and higher harmonic growth.

[10] The analytic solutions presented by FA94 are for shallow, "funnel-shaped" estuaries, and the advancement of the tide is controlled primarily by friction and channel morphology [LeBlond, 1978; Friedrichs and Madsen, 1992; Savenije et al., 2008]. At lowest order, gradients in cross-sectional area dominate gradients in along-channel velocity $\left(L_{A}<L_{U}\right.$, where $\left.1 / L_{U} \approx-\frac{1}{U} \frac{\partial U}{\partial x}\right)$ in the cross-sectionally integrated continuity equation and friction is more important than inertia in the momentum equation [Friedrichs and Madsen, 1992]; the resulting one-dimensional wave equation for tidal elevation

$$
\frac{\partial \zeta}{\partial t}+\frac{\bar{c}_{0}^{2}}{L_{A} r} \frac{\partial \zeta}{\partial x}=0
$$

has the solution given by equation (1), with frequencydependent celerity

$$
c_{n}=\frac{\bar{c}_{0}^{2}}{L_{A} r_{n}}=\frac{\omega_{n}}{k_{n}} .
$$

The frictionless wave speed in channels with intertidal storage is

$$
\bar{c}_{0}=\sqrt{g \bar{A} / \bar{b}}
$$

where the overbar denotes a mean tidal cycle quantity. Quadratic friction

$$
r_{n} \equiv C_{d, n} \frac{8}{3 \pi} \frac{U_{\mathrm{M}_{2}}}{h}
$$

is constant and linearized, and scaled to the dominant $\mathrm{M}_{2}$ velocity amplitude $U_{\mathrm{M}_{2}} \approx a_{M_{2}} \omega_{M_{2}} L_{A} \bar{b} / \bar{A}$. $L_{A}$ is found by fitting an exponential function of a form $e^{-x / L_{A}}$ to along-channel values of cross-sectional area. $8 / 3 \pi$ in equation (5) comes from the Fourier expansion of the quadratic drag formula- tion [Pingree, 1983; Godin, 1991], and the drag coefficient $C_{d, n}$ is frequency-specific [Pingree and Griffiths, 1987; Inoue and Garrett, 2007]. At lowest order, the observed celerity (3) for each constituent is the frictionless wave speed squared modified by friction and channel convergence.

[11] In equation (2), the terms in the coefficient are assumed constant: spatially they represent estuary-wide characteristics, and terms that vary with the tidal cycle (namely depth and estuary width) have been time-averaged. From equation (3), the delay in the waveform for each constituent is

$$
k_{n}=\frac{\omega_{n} L_{A} r}{\bar{c}_{0}^{2}}=\frac{\omega_{n} L_{A}}{g(\bar{A} / \bar{b})} C_{d, n} \frac{8}{3 \pi} \frac{U_{M_{2}}}{h}=\frac{\omega_{n} \bar{b}}{g \bar{A}} L_{A}^{2} C_{d, n} \frac{8}{3 \pi} \frac{\omega_{M_{2}} a_{M_{2}}}{h} .
$$

The wave number (and hence delay) increases with higher frequency, more drag, a less-convergent channel (larger $L_{A}$ ), wider intertidal area, shallower channel, and/or smaller crosssectional channel area. It is this frequency-dependent celerity that requires examination in terms of the relative phase shifts within an estuary.

[12] At second order, finite amplitude effects ( $a / h$ for depth variations; $(\bar{b}-B) / \bar{b}$ for estuary width variations), velocity gradients due to wave propagation $\left(\left|L_{A} / L_{U}\right|\right)$, along-channel phase delay $\left(k L_{A}\right)$, and local acceleration $(\omega / r)$ become important. The finite amplitude effects are the largest contributors to nonlinearities [FA94], and this may be expressed through a time-dependent wave speed

$$
\begin{aligned}
\frac{c_{0}^{2}}{L_{A} r} & =\frac{g B H(t)}{L_{A} r b(t)}=\frac{g B[h+\zeta(t)]}{L_{A} r\left[\bar{b}+(\bar{b}-B) \frac{\zeta(t)}{a}\right]}=\frac{g B h\left[1+\frac{a}{h} \frac{\zeta(t)}{a}\right]}{L_{A} r \bar{b}\left[1+\frac{(\bar{b}-B)}{\bar{b}} \frac{\zeta(t)}{a}\right]} \\
& \approx \frac{\bar{c}_{0}^{2}}{L_{A} r}\left(1+\frac{\gamma \zeta(t)}{a}\right)
\end{aligned}
$$

where the tidal asymmetry factor

$$
\gamma=(1+\alpha) \frac{a}{h}-\frac{\bar{b}-B}{\bar{b}}
$$

parameterizes the relative importance of depth and estuary width changes over a tidal cycle [Friedrichs and Madsen, 1992]. For a mixed, semidiurnal system I take $a$ to be onehalf the diurnal tide range between MHHW and MLLW. The weighting coefficient $\alpha$ can be used to tune the relative importance of depth variations to account for depthdependence in the friction term and time-dependence in $C_{d}$ that have been neglected (for a thorough discussion, see Friedrichs and Madsen [1992]).

[13] Incorporating the second order parameters (see FA94 for further details), the wave equation at second order is

$$
\frac{\partial \zeta}{\partial t}-\frac{\bar{c}}{1+i \nu}\left(1+\frac{\gamma \zeta}{a}\right) \frac{\partial \zeta}{\partial x}=0
$$

where the amplitude growth factor is given as

$$
\nu=k L_{A}\left[\left(\frac{c}{c_{0}}\right)^{2}-1\right] .
$$

Equation (8) is identical in form to equation (2), with the exception that the wave speed now varies with the tidal cycle [LeBlond, 1978], scaled by $\gamma$. When $\gamma<0$, temporal 
changes in estuary width are dynamically more significant than relative changes in depth. Physically, the advancement of high water is slowed relative to low water based on the assumption that the shoals do not carry momentum. Mathematically, in equation (8), wave speed is slowest at high water when, for $\gamma<0, \gamma \zeta / a=\gamma \cos (w t)$ reaches its minimum value, allowing the trough to catch up to the wave crest. Neglecting principal tide asymmetry, this produces a duration asymmetry where the time of falling water is shorter than rising water, and so the tide is ebb-dominant with the magnitude of $\partial \zeta / \partial t=\zeta^{\prime}$ larger on ebb [Boon and Byrne, 1981]. The reverse scenario occurs for $\gamma>0$ : for large $a / h$, the variation in friction over a tidal cycle slows the advancement of the trough at low water more readily than at high water; the crest catches up to the trough and the period of falling water is longer, producing flood-dominant currents [Speer and Aubrey, 1985; Dronkers, 1986].

[14] This distortion of the tide over a tidal cycle can be represented by combining the principal tides with overtides and compound tides. We are interested in how this effect is manifest in a mixed, semidiurnal environment where the presence of several large principal tides contributes to a larger complement of higher harmonic constituents. Here I have presented a brief overview of the physics relevant to the topic. In the following section I examine the sources of asymmetry in mixed, semidiurnal estuaries with the preceding equations.

\section{Asymmetry}

\subsection{Skewness}

[15] I quantify asymmetry as the normalized sample skewness of the tidal elevation time derivative $\left(\partial \zeta / \partial t=\zeta^{\prime}\right)$

$$
\gamma_{1} \equiv \frac{\mu_{3}}{\sigma^{3}}=\frac{\frac{1}{\tau-1} \sum_{t=1}^{\tau}\left(\zeta_{t}^{\prime}-\bar{\zeta}^{\prime}\right)^{3}}{\left[\frac{1}{\tau-1} \sum_{t=1}^{\tau}\left(\zeta_{t}^{\prime}-\bar{\zeta}^{\prime}\right)^{2}\right]^{3 / 2}}
$$

where $\mu_{3}$ is the third sample moment about the mean and $\sigma$ is the standard deviation, the square-root of the second sample moment about the mean [cf. Emery and Thomson, 2001]. The summation is for $\tau$ observations from time $t=1$ to $t=\tau$. Ebb-tide duration is shorter for $\gamma_{1}<0$ and floodtide duration is shorter for $\gamma_{1}>0$; assuming the dominant elevation and velocity components to be in quadrature, this duration asymmetry may be manifest as tidal current asymmetry. The skewness of an entire record quantifies the mean asymmetry over the duration of the observations; a short window can be used to produce a time series of skewness (akin to producing a running-mean). When computing a runningskewness time series, using the standard deviation of the entire record (rather than of just the window) retains some of the amplitude information that is otherwise lost by normalizing. By taking the time derivative of the tidal elevation record, the skewness reflects the duration asymmetry in the rise $\left(\zeta^{\prime}>0\right)$ and fall $\left(\zeta^{\prime}<0\right)$ of water level.

[16] Skewness can also be computed for a velocity time series directly from the record (i.e., without taking the time derivative); in this case, currents are ebb-dominant for $\gamma_{1}<0$ and flood-dominant for $\gamma_{1}>0$. Because tidal elevation and tidal currents are generally $90^{\circ}$ out of phase in the systems of interest, the skewness computed from $\zeta^{\prime}$ will be similar to that computed from $U$ in the absence of river flow, stratification, or bathymetric effects. One advantage to quantifying asymmetry via tidal elevation is that bathymetry can produce local asymmetries in tidal currents that are generally not manifest in the free surface record [Godin, 1991]. Additionally, observations of tidal elevation are much more readily available than long-term observations of currents. While duration asymmetry in tidal elevation does not guarantee asymmetry in velocity, the skewness of the tidal elevation time derivative still provides useful information about the tidal forcing and response of an estuary.

[17] Note that the calculation of the skewness is not time invariant, as the choice of window length or starting point relative to tidal stage can affect the skewness. The sensitivity of the calculation to the starting point is minimized if the window length is an integer multiple of the mean lunar day (24.84 hours); for a record comprised of hourly samples, an integer multiple of a 25-hour window is sufficient. If the window length is too long, spring-neap changes in asymmetry begin to be averaged out. The decorrelation time for a sinusoid with a fortnightly period (i.e., the first zero crossing of an autocovariance function) suggests a window length of three lunar days as an upper bound. In the following section I will show how the traditional metrics of asymmetry, namely the ratio of constituent amplitudes and the difference in constituent phases, arise from the calculation of sample skewness.

\subsection{Asymmetry From Principal Tidal Constituents}

[18] I first consider asymmetry created by the principal constituents of the diurnal and semidiurnal bands. For example, combining $\mathrm{M}_{2}$ and $\mathrm{K}_{1}$ produces a tide with a diurnal inequality, where one semidiurnal high tide is higher or lower than the one preceding it; this diurnal inequality produces ebb-dominance through half of a 13.66-day cycle and flooddominance through the other half (Figure 3a, black line). The amplitude of a diurnal tide created by combining $\mathrm{K}_{1}$ and $\mathrm{O}_{1}$ also has 13.66-day periodicity (Figure 3a, gray line). When $\mathrm{K}_{1}$ and $\mathrm{O}_{1}$ are aligned at spring tides, the diurnal inequality produced by the $\mathrm{K}_{1} / \mathrm{O}_{1} / \mathrm{M}_{2}$ triad is maximized; neap tides (when $\mathrm{K}_{1}$ and $\mathrm{O}_{1}$ are out of phase) minimize the diurnal inequality. Consequently, the phase alignment of the diurnal and semidiurnal tides determines whether the floodor ebb-dominant diurnal inequality is amplified. In California, the diurnal tides align to produce ebb-dominant spring tides and weakly flood-dominant neap tides (Figure $3 b$ ). The modulation introduced by $\mathrm{S}_{2}, \mathrm{P}_{1}$, and $\mathrm{N}_{2}$ further affects this asymmetry on fortnightly to semiannual time scales (not shown).

[19] To examine the tidal triad asymmetry more rigorously, the frequencies of the principal constituents can be expressed in terms of their Doodson frequencies [Doodson, 1921; Hoitink et al., 2003]

$$
\begin{gathered}
\zeta_{\mathrm{K}_{1}}=a_{\mathrm{K}_{1}} \cos \left[\left(\omega_{1}+\omega_{2}\right) t-\varphi_{\mathrm{K}_{1}}\right], \\
\zeta_{\mathrm{O}_{1}}=a_{\mathrm{O}_{1}} \cos \left[\left(\omega_{1}-\omega_{2}\right) t-\varphi_{\mathrm{O}_{1}}\right], \\
\zeta_{\mathrm{M}_{2}}=a_{\mathrm{M}_{2}} \cos \left(2 \omega_{1} t-\varphi_{\mathrm{M}_{2}}\right),
\end{gathered}
$$

where $2 \pi / \omega_{1}$ is the period of the mean lunar day ( 24.84 hours) and $2 \pi / \omega_{2}$ the sidereal month (27.32 mean solar days). The diurnal constituents share a common Doodson frequency $\left(\omega_{1}\right)$ 
(a) principal tide interactions

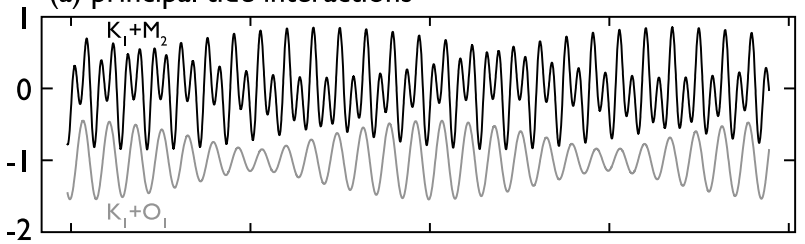

(b) principal tide triad $\left(\mathrm{K}_{1}+\mathrm{O}_{1}+\mathrm{M}_{2}\right)$

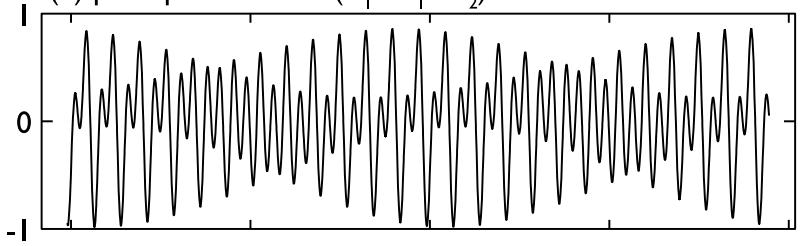

(c) skewness and amplitude

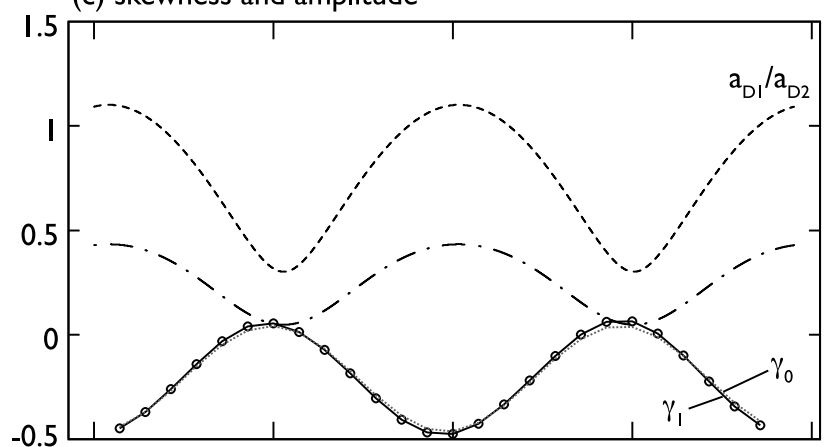

(d) phase

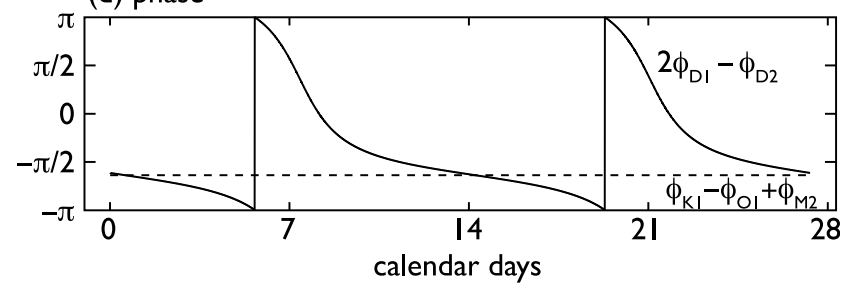

Figure 3. Example of tidal asymmetry created from principal tides: $a_{\mathrm{M}_{2}}=0.5 \mathrm{~m}, a_{\mathrm{K}_{1}}=0.35 \mathrm{~m}, a_{\mathrm{O}_{1}}=0.2 \mathrm{~m}, \phi_{\mathrm{M}_{2}}=$ $180^{\circ}, \phi_{\mathrm{K}_{1}}=220^{\circ}, \phi_{\mathrm{O}_{1}}=205^{\circ}$. (a) Resonance between $\mathrm{K}_{1}+$ $\mathrm{M}_{2}$ (black line) and $\mathrm{K}_{1}+\mathrm{O}_{1}$ (gray line). (b) Resultant tide. (c) Skewness computed with one-lunar-day window using equation (10) (black solid line with circles) and approximated with equation (17) (gray dotted line). The ratio of amplitudes from equation (17) (black dash-dotted line) is similar to the ratio of amplitudes $a_{\mathrm{D}_{1}} / a_{\mathrm{D}_{2}}$ (black dashed line). (d) Time-dependent phase difference in equation (17) (solid line), compared to constituent phase difference (dashed line), shows most asymmetric tides occur when $2 \phi_{\mathrm{D}_{1}}-\phi_{\mathrm{D}_{2}}$ approaches $\phi_{\mathrm{K}_{1}}+\phi_{\mathrm{O}_{1}}-\phi_{\mathrm{M}_{2}}$.

and trigonometric identities can be used to combine $\mathrm{K}_{1}$ and $\mathrm{O}_{1}$ into a single equation for the diurnal tide [Hoitink et al., 2003]

$$
\zeta_{\mathrm{D}_{1}}=\zeta_{\mathrm{K}_{1}}+\zeta_{\mathrm{O}_{1}}=a_{\mathrm{D}_{1}}(t) \cos \left[\omega_{1} t-\phi_{\mathrm{D}_{1}}(t)\right]
$$

where

$$
a_{\mathrm{D}_{1}}(t)=\left[a_{\mathrm{K}_{1}}^{2}+a_{\mathrm{O}_{1}}^{2}+2 a_{\mathrm{K}_{1}} a_{\mathrm{O}_{1}} \cos \left(2 \omega_{2} t+\varphi_{\mathrm{O}_{1}}-\varphi_{\mathrm{K}_{1}}\right)\right]^{1 / 2}
$$

and

$$
\phi_{\mathrm{D}_{1}}(t)=-\arctan \left[\frac{a_{\mathrm{K}_{1}} \sin \left(\omega_{2} t-\varphi_{\mathrm{K}_{1}}\right)-a_{\mathrm{O}_{1}} \sin \left(\omega_{2} t+\varphi_{\mathrm{O}_{1}}\right)}{a_{\mathrm{K}_{1}} \cos \left(\omega_{2} t-\varphi_{\mathrm{K}_{1}}\right)+a_{\mathrm{O}_{1}} \cos \left(\omega_{2} t+\varphi_{\mathrm{O}_{1}}\right)}\right] .
$$

The equivalent form of the semidiurnal tide is

$$
\zeta_{\mathrm{D}_{2}}=a_{\mathrm{M}_{2}} \cos \left(2 \omega_{1} t-\varphi_{\mathrm{M}_{2}}\right)=a_{2} \cos \left(2 \omega_{1} t-\phi_{2}\right) .
$$

The subscripts $\mathrm{D}_{1}$ and $\mathrm{D}_{2}$ indicate diurnal and semidiurnal terms, respectively, and the four quadrant arctangent is evaluated for $\phi_{\mathrm{D}_{1}}$. To illustrate this with an example, I will use amplitudes and phases representative of the California coast: $a_{\mathrm{M}_{2}}=0.5 \mathrm{~m}, a_{\mathrm{K}_{1}}=0.35 \mathrm{~m}, a_{\mathrm{O}_{1}}=0.2 \mathrm{~m}, \phi_{\mathrm{M}_{2}}=180^{\circ}, \phi_{\mathrm{K}_{1}}=$ $220^{\circ}, \phi_{\mathrm{O}_{1}}=205^{\circ}$. The resultant tide $\zeta=\zeta_{\mathrm{D}_{1}}+\zeta_{\mathrm{D}_{2}}$ is shown in Figure $3 \mathrm{~b}$.

[20] Both $a_{\mathrm{D}_{1}}$ and $\phi_{\mathrm{D}_{1}}$ have 13.66 day periodicity (Figures $3 \mathrm{c}$ 3d). Sample skewness (Figure 3c, solid line with circles) computed with a one lunar-day moving window shows that ebb-dominance is greatest during spring tides, and that the neap tides are weakly flood-dominant. The skewness of the entire month-long record is negative and so reflects the net ebb-dominance.

[21] Two metrics have been previously used to describe tidal asymmetry: an amplitude ratio $a_{\mathrm{D}_{1}} / a_{\mathrm{D}_{2}}$, which expresses the degree of asymmetry; and the phase difference $2 \phi_{\mathrm{D}_{1}}-\phi_{\mathrm{D}_{2}}$, which indicates the direction of asymmetry [Speer and Aubrey, 1985; Hoitink et al., 2003]. Note that the interaction between the semidiurnal and quarter-diurnal bands is mathematically similar to the interaction between diurnal and semidiurnal bands. Both $a_{\mathrm{D}_{1}} / a_{\mathrm{D}_{2}}$ and $\left|\gamma_{1}\right|$ are large during spring tides and small during neap tides (Figure $3 \mathrm{c}$ ); there is a slight phase difference between $a_{\mathrm{D}_{1}} / a_{\mathrm{D}_{2}}$ and $\gamma_{1}$ because the phase of $a_{\mathrm{D}_{1}}$ is not affected by the relative magnitudes of $\mathrm{K}_{1}$ and $\mathrm{O}_{1}$ in equation (12b), whereas the asymmetry is sensitive to the different amplitudes through $\phi_{\mathrm{D}_{1}}$ (equation (12c)). Skewness $\gamma_{1}$ is negative (shorter ebb duration) for $-\pi<2 \phi_{\mathrm{D}_{1}}-\phi_{\mathrm{D}_{2}}<0$, and positive (shorter flood duration) for $0<2 \phi_{\mathrm{D}_{1}}-\phi_{\mathrm{D}_{2}}<\pi$ (Figure 3d). While the asymmetry and phase difference both vary over the fortnightly cycle, the uneven distributions of both $\gamma_{1}$ and $2 \phi_{\mathrm{D}_{1}}-\phi_{\mathrm{D}_{2}}$ indicate that the mean tidal cycle asymmetry produces shorterduration ebbs. I will next show how these two relationships, the amplitude ratio and the phase difference, are actually parameters that arise from the third moment, and that the information they convey individually is conveniently measured with $\gamma_{1}$.

[22] The time-average of a sinusoid with constant amplitude and phase is zero if an averaging period equal to the sinusoid period is chosen (i.e., $\bar{\zeta}=\int_{0}^{2 \pi / \omega} \cos (\omega t) d t=0$ ). Additionally, as $t \rightarrow \infty, \bar{\zeta} \rightarrow 0$. Thus, by considering skewness with either window lengths of $2 \pi / \omega_{1}$ (a lunar day) or at long times, $\bar{\zeta}^{\prime} \approx 0$ and equation (10) can be approximated as

$$
\gamma_{1} \approx \frac{\frac{1}{N-1} \sum_{t=1}^{N}\left(\zeta_{t}^{\prime}\right)^{3}}{\left[\frac{1}{N-1} \sum_{t=1}^{N}\left(\zeta_{t}^{\prime}\right)^{2}\right]^{3 / 2}}
$$

Although the phase and amplitude of $\zeta_{\mathrm{D}_{1}}$ are not timeinvariant, the analytic approximation is very close to the true 


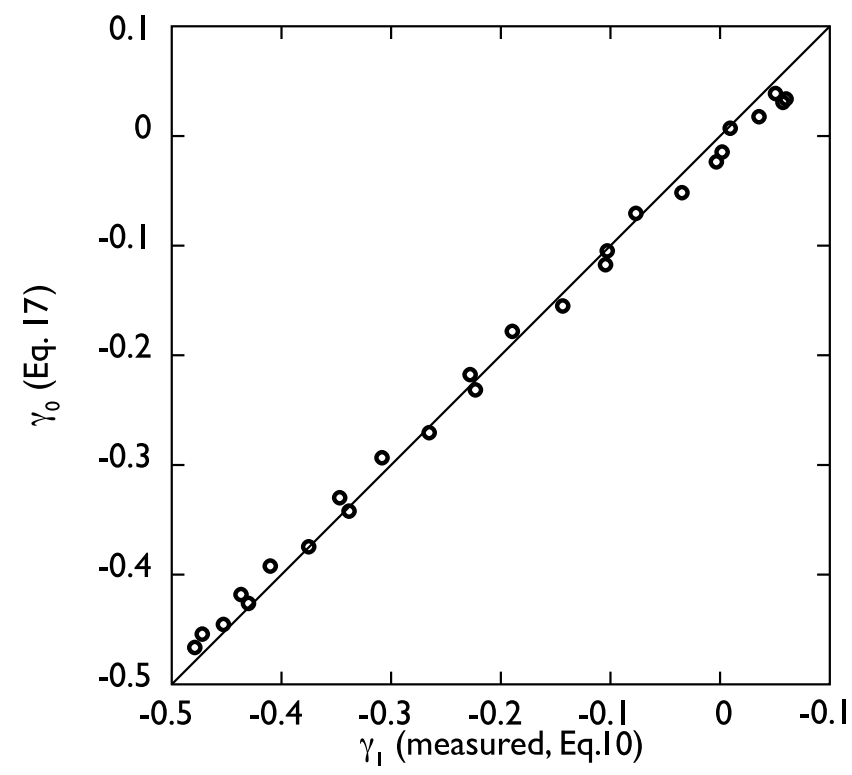

Figure 4. Scatter plot of skewness $\gamma_{1}$ (equation (10)) and an approximation $\gamma_{0}$ (equation (17)), from the example in Figure 3. Solid line is $1: 1$ ratio.

skewness computed in equation (10). It is worth noting that often $\bar{U} \neq 0$, and so the simplification in equation (14) may have a larger error if a time series of $U$ is considered.

[23] Evaluating the derivative and expanding $\zeta^{\prime 3}=\left(\zeta_{\mathrm{D}_{1}}^{\prime}+\right.$ $\left.\zeta_{\mathrm{D}_{2}}^{\prime}\right)^{3}=\zeta_{\mathrm{D}_{1}}^{\prime 3}+3 \zeta_{\mathrm{D}_{1}}^{\prime 2} \zeta_{\mathrm{D}_{2}}^{\prime}+3 \zeta_{\mathrm{D}_{1}}^{\prime} \zeta_{\mathrm{D}_{2}}^{\prime 2}+\zeta_{\mathrm{D}_{2}}^{\prime 3}$, the terms that go into the approximation of the third moment in equation (14) are

$$
\begin{aligned}
\zeta^{\prime 3}= & -\frac{1}{4} a_{\mathrm{D}_{1}}^{3} \omega_{1}^{3}\left[3 \sin \left(\omega_{1} t-\phi_{\mathrm{D}_{1}}\right)-\sin \left(3 \omega_{1} t-3 \phi_{\mathrm{D}_{1}}\right)\right] \\
& +\frac{3}{2} a_{\mathrm{D}_{1}}^{2} a_{\mathrm{D}_{2}} \omega_{1}^{3}\left[\sin \left(4 \omega_{1} t-2 \phi_{\mathrm{D}_{1}}-\phi_{\mathrm{D}_{2}}\right)+\sin \left(2 \phi_{\mathrm{D}_{1}}-\phi_{\mathrm{D}_{2}}\right)\right. \\
& \left.-2 \sin \left(2 \omega_{1} t-\phi_{\mathrm{D}_{2}}\right)\right]-3 a_{\mathrm{D}_{1}} a_{\mathrm{D}_{2}}^{2} \omega_{1}^{3}\left[\sin \left(3 \omega_{1} t+\phi_{\mathrm{D}_{1}}-2 \phi_{\mathrm{D}_{2}}\right)\right. \\
& \left.+2 \sin \left(\omega_{1} t-\phi_{\mathrm{D}_{1}}\right)-\sin \left(5 \omega_{1} t-\phi_{\mathrm{D}_{1}}-2 \phi_{\mathrm{D}_{2}}\right)\right] \\
& -2 a_{\mathrm{D}_{2}}^{3} \omega_{1}^{3}\left[3 \sin \left(2 \omega_{1} t-\phi_{\mathrm{D}_{2}}\right)-\sin \left(6 \omega_{1} t-3 \phi_{\mathrm{D}_{2}}\right)\right]
\end{aligned}
$$

and the terms that go into the approximation of the second moment in equation (14) are

$$
\begin{aligned}
\zeta^{\prime 2}= & \frac{1}{2} a_{\mathrm{D}_{1}}^{2} \omega_{1}^{2}\left[1-\cos \left(2 \omega_{1} t-2 \phi_{\mathrm{D}_{1}}\right)\right] \\
& +2 a_{\mathrm{D}_{1}} a_{\mathrm{D}_{2}} \omega_{1}^{2}\left[\cos \left(\omega_{1} t+\phi_{\mathrm{D}_{1}}-\phi_{\mathrm{D}_{2}}\right)\right. \\
& \left.-\cos \left(3 \omega_{1} t-\phi_{\mathrm{D}_{1}}-\phi_{\mathrm{D}_{2}}\right)\right] \\
& +2 a_{\mathrm{D}_{2}}^{2} \omega_{1}^{2}\left[1+\cos \left(4 \omega_{1} t-2 \phi_{\mathrm{D}_{2}}\right)\right] .
\end{aligned}
$$

[24] Taking the mean of equation (15), only the second term on the second line has no periodicity at $\omega_{1}$ and so the third moment may be reasonably approximated by $\frac{3}{2} a_{\mathrm{D}_{1}}^{2} a_{\mathrm{D}_{2}} \omega_{1}^{3}$ $\sin \left(2 \phi_{\mathrm{D}_{1}}-\phi_{\mathrm{D}_{2}}\right)$. Likewise, the second moment may be approximated as $\left[\frac{1}{2} \omega_{1}^{2}\left(a_{\mathrm{D}_{1}}{ }^{2}+4 a_{\mathrm{D}_{2}}{ }^{2}\right)\right]$. Combining these two terms, an analytical approximation for the skewness created by a diurnal/semidiurnal interaction is

$$
\gamma_{0}=\frac{\frac{3}{2} a_{\mathrm{D}_{1}}^{2} a_{\mathrm{D}_{2}} \sin \left(2 \phi_{\mathrm{D}_{1}}-\phi_{\mathrm{D}_{2}}\right)}{\left[\frac{1}{2}\left(a_{\mathrm{D}_{1}}^{2}+4 a_{\mathrm{D}_{2}}^{2}\right)\right]^{3 / 2}} .
$$

The skewness approximated with $\gamma_{0}$ is nearly identical to the true skewness measured by $\gamma_{1}$ (Figure 4 ). The analytic approximation in equation (17) shows why the traditional metrics are effective at quantifying asymmetry. $a_{\mathrm{D}_{1}} / a_{\mathrm{D}_{2}}$ and the amplitude ratio $a_{\mathrm{D}_{1}}^{2} a_{\mathrm{D}_{2}} /\left(a_{\mathrm{D}_{1}}^{2}+a_{\mathrm{D}_{2}}\right)^{3 / 2}$ from equation (17) have the same periodicity and amplitude throughout the spring-neap cycle (Figure $3 \mathrm{c}$ ), while $2 \phi_{D_{1}}-\phi_{\mathrm{D}_{2}}$ is the only phase information retained in equation (17). A similar elaboration can be conducted for asymmetry in a quarter diurnalsemidiurnal interaction simply by substituting $M_{2}$ for $D_{1}$ terms and $\mathrm{M}_{4}$ for $\mathrm{D}_{2}$ terms.

[25] The direction of asymmetry is important for residual sediment bed load transport, which is proportional to $\overline{U^{3}}$ [Bagnold, 1966]. Hoitink et al. [2003] showed that the direction asymmetry generated by $\mathrm{K}_{1}, \mathrm{O}_{1}$, and $\mathrm{M}_{2}$ was given by $\cos \left(\phi_{\mathrm{K}_{1}}+\phi_{\mathrm{O}_{1}}-\phi_{\mathrm{M}_{2}}\right)$. Taking the time average of velocity cubed is a reasonable approximation of the third sample moment equation (14), and so the maximum asymmetry occurs when the phase $2 \phi_{\mathrm{D}_{1}}-\phi_{\mathrm{D}_{2}}$ is equal to $\phi_{\mathrm{K}_{1}}+$ $\phi_{\mathrm{O}_{1}}-\phi_{\mathrm{M}_{2}}$ (Figures $3 \mathrm{c}-3 \mathrm{~d}$ ). While I have cast this discussion in terms of the sample skewness, simply taking the third moment about the mean of either velocity or elevation timederivative observations may be a more natural quantification, as normalizing the third moment with the standard deviation may remove some of the magnitude information relevant to sediment transport potential. Normalizing the third moment of a lunar day window with the standard deviation of the entire data set may be another method of retaining magnitude information.

[26] I have shown how the metrics used in parameterizing asymmetry come from the definition of the third moment; calculating the skewness, either as time-varying runningskewness or as the skewness of an entire data set, is a natural straightforward method for quantifying asymmetry in observations that conveniently captures the amplitude and phase information embodied in traditional metrics of asymmetry.

\subsection{Asymmetry From Nonlinearities}

[27] The skewness can be used to quantify how harmonics created by nonlinearities augment or cancel asymmetry imposed by principal tides. The amplitude and phase of the overtides and compound tides are affected by estuarine geometry directly through $\gamma$ and the wave number of the principal tides. This may be seen by expansion of the second-order term $\zeta \frac{\partial \zeta}{\partial x}$ in the wave equation (8), which may be evaluated to second order by substituting the first-order solution for $\zeta$ (1). For a single tidal constituent, this is straightforward and the use of trigonometric identities yields the first overtide [FA94]. Taking for illustrative purposes $\zeta=\zeta_{\mathrm{M}_{2}}+\zeta_{\mathrm{K}_{1}}$, a larger set of overtides and compound tides are produced by the nonlinear term

$$
\begin{aligned}
\zeta \frac{\partial \zeta}{\partial x}= & \left(\zeta_{\mathrm{M}_{2}}+\zeta_{\mathrm{K}_{1}}\right)\left(\frac{\partial \zeta_{\mathrm{M}_{2}}}{\partial x}+\frac{\partial \zeta_{\mathrm{K}_{1}}}{\partial x}\right) \\
= & \zeta_{\mathrm{M}_{2}} \frac{\partial \zeta_{\mathrm{M}_{2}}}{\partial x}+\zeta_{\mathrm{M}_{2}} \frac{\partial \zeta_{\mathrm{K}_{1}}}{\partial x}+\zeta_{\mathrm{K}_{1}} \frac{\partial \zeta_{\mathrm{M}_{2}}}{\partial x}+\zeta_{\mathrm{K}_{1}} \frac{\partial \zeta_{\mathrm{K}_{1}}}{\partial x} \\
= & -\frac{1}{2} a_{\mathrm{M}_{2}}^{2} k_{\mathrm{M}_{2}} \sin \left(2 \omega_{\mathrm{M}_{2}} t-2 k_{\mathrm{M}_{2}} x-2 \phi_{\mathrm{M}_{2}}\right) \\
& -\frac{1}{2} a_{\mathrm{M}_{2}} a_{\mathrm{K}_{1}} k_{\mathrm{K}_{1}}\left\{\operatorname { s i n } \left[\left(\omega_{\mathrm{K}_{1}}-\omega_{\mathrm{M}_{2}}\right) t-\left(k_{\mathrm{K}_{1}}-k_{\mathrm{M}_{2}}\right) x\right.\right. \\
& \left.-\phi_{\mathrm{K}_{1}}+\phi_{\mathrm{M}_{2}}\right]+\sin \left[\left(\omega_{\mathrm{K}_{1}}+\omega_{\mathrm{M}_{2}}\right) t-\left(k_{\mathrm{K}_{1}}+k_{\mathrm{M}_{2}}\right) x\right.
\end{aligned}
$$




$$
\begin{aligned}
& \left.\left.-\phi_{\mathrm{K}_{1}}-\phi_{\mathrm{M}_{2}}\right]\right\}-\frac{1}{2} a_{\mathrm{M}_{2}} a_{\mathrm{K}_{1}} k_{\mathrm{M}_{2}}\left\{\operatorname { s i n } \left[\left(\omega_{\mathrm{M}_{2}}-\omega_{\mathrm{K}_{1}}\right) t\right.\right. \\
& \left.-\left(k_{\mathrm{M}_{2}}-k_{\mathrm{K}_{1}}\right) x-\phi_{\mathrm{K}_{1}}+\phi_{\mathrm{M}_{2}}\right]+\sin \left[\left(\omega_{\mathrm{M}_{2}}+\omega_{\mathrm{K}_{1}}\right) t\right. \\
& \left.\left.-\left(k_{\mathrm{M}_{2}}+k_{\mathrm{K}_{1}}\right) x-\phi_{\mathrm{K}_{1}}-\phi_{\mathrm{M}_{2}}\right]\right\} \\
& -\frac{1}{2} a_{\mathrm{K}_{1}}^{2} k_{\mathrm{K}_{1}} \sin \left(2 \omega_{\mathrm{K}_{1}} t-2 k_{\mathrm{K}_{1}} x-2 \phi_{\mathrm{K}_{1}}\right) .
\end{aligned}
$$

Inserting equation (18) into (8) produces an equation that is linear in $\zeta$ and can be separated into individual frequencies and re-written as a set of individual equations with solutions

$$
\begin{gathered}
\zeta_{\mathrm{M}_{2}}=a_{\mathrm{M}_{2}} e^{\nu_{\mathrm{M}_{2}} k_{\mathrm{M}_{2}} x} \cos \left(\omega_{\mathrm{M}_{2}} t-k_{\mathrm{M}_{2}} x-\phi_{\mathrm{M}_{2}}\right)+\theta_{\mathrm{M}_{2}}, \\
\zeta_{\mathrm{K}_{1}}=a_{\mathrm{K}_{1}} e^{\nu_{\mathrm{K}_{1}} k_{\mathrm{K}_{1}} x} \cos \left(\omega_{\mathrm{K}_{1}} t-k_{\mathrm{K}_{1}} x-\phi_{\mathrm{K}_{1}}\right)+\theta_{\mathrm{K}_{1}}, \\
\zeta_{\mathrm{M}_{4}}=-\frac{1}{2} \frac{\gamma}{a} a_{\mathrm{M}_{2}}^{2} k_{\mathrm{M}_{2}} x \sin \left(2 \omega_{\mathrm{M}_{2}} t-2 k_{\mathrm{M}_{2}} x-2 \phi_{\mathrm{M}_{2}}\right)+\theta_{\mathrm{M}_{4}}, \quad(19 \mathrm{c}) \\
\zeta_{\mathrm{MK}_{3}}=-\frac{1}{2} \frac{\gamma}{a} a_{\mathrm{M}_{2}} a_{\mathrm{K}_{1}}\left(k_{\mathrm{M}_{2}}+k_{\mathrm{K}_{1}}\right) x \sin \left[\left(\omega_{\mathrm{M}_{2}}+\omega_{\mathrm{K}_{1}}\right) t\right. \\
\left.-\left(k_{\mathrm{M}_{2}}+k_{\mathrm{K}_{1}}\right) x-\phi_{\mathrm{K}_{1}}-\phi_{\mathrm{M}_{2}}\right]+\theta_{\mathrm{MK}_{3}}, \\
\zeta_{\mathrm{O}_{1}}=-\frac{1}{2} \frac{\gamma}{a} a_{\mathrm{M}_{2}} a_{\mathrm{K}_{1}}\left(k_{\mathrm{M}_{2}}-k_{\mathrm{K}_{1}}\right) x \sin \left[\left(\omega_{\mathrm{K}_{1}}-\omega_{\mathrm{M}_{2}}\right) t-\left(k_{\mathrm{K}_{1}}-k_{\mathrm{M}_{2}}\right) x\right. \\
-\frac{\left.\phi_{\mathrm{K}_{1}}+\phi_{\mathrm{M}_{2}}\right]+\theta_{\mathrm{O}_{1}},}{\zeta_{\mathrm{K}_{2}}=}-\frac{1}{2} \frac{\gamma}{a} a_{\mathrm{K}_{1}}^{2} k_{\mathrm{K}_{1}} x \sin \left(2 \omega_{\mathrm{K}_{1}} t-2 k_{\mathrm{K}_{1}} x-2 \phi_{\mathrm{K}_{1}}\right)+\theta_{\mathrm{K}_{2}}, \quad(19 \mathrm{f})
\end{gathered}
$$

where $\theta_{n}$ is the contribution from any harmonic already present at $x=0$ [FA94].

[28] At second order, the principal tides $\left(\zeta_{\mathrm{M}_{2}}\right.$ and $\zeta_{\mathrm{K}_{1}}$ in this simplified example) decay exponentially with increasing distance into the estuary while the higher harmonics increase in amplitude with distance into the estuary, scaled by the asymmetry factor $\gamma$. Although set (19) implies that both the phase delay and higher harmonic amplitude growth will be linear with distance, the actual advancement may more accurately be described as a nonlinear diffusion phenomenon [Friedrichs and Madsen, 1992], rather than as an advective phenomenon in equation (8). The error in the solutions is greatest within $L_{A}$ of the head of the estuary or areas of appreciable bathymetric change where the neglected $\partial U / \partial x$ from the continuity equation may be significant. Phase lags may also appear to be nonlinear as the observed phase is a combination of multiple sources of nonlinearity: friction in the momentum equation leads to a different phase relationship than do depth and width changes in the continuity equation [Heath, 1980] and feedback from nonlinear distortion to fundamental frequencies (as in the case of $\mathrm{O}_{1}$ in equation (19e)) further precludes simple interpretation of observations [Godin, 1991]. Set (19) is provided only as a simplified example of how morphology affects the harmonics, and not as an exhaustive solution set.

[29] The effect of nonlinearities on asymmetry in mixed, mainly semidiurnal estuaries can be demonstrated by con- structing a simple tide using just five constituents: the three principal tides $\mathrm{K}_{1}$ (equation (19b)), $\mathrm{O}_{1}\left(\zeta_{\mathrm{O}_{1}}=a_{\mathrm{O}_{1}} e^{\nu_{\mathrm{O}_{1}} k_{\mathrm{O}_{1}} x} \cos \right.$ $\left(\omega_{\mathrm{O}_{1}} t-k_{\mathrm{O}_{1}} x\right)$ ), and $\mathrm{M}_{2}$ (equation (19a)), as well as the $\mathrm{M}_{4}$ overtide (equation (19c)), and the $\mathrm{MK}_{3}$ compound tide (equation (19d)). For simplicity, the drag coefficient is the same for all constituents. Additionally, feedback to the principal tides from nonlinearities is neglected (e.g., equation (19e) is ignored). While in specific situations this feedback could be important, set (19) with the amplitudes and phases described following indicates that the amplitude of the nonlinear feedback to $\mathrm{O}_{1}$ is two orders of magnitude smaller than the amplitude of $\mathrm{O}_{1}$ at the boundary, and an order or magnitude smaller than either $\mathrm{MK}_{3}$ or $\mathrm{M}_{4}$. The amplitudes and phases of the principal tides are the same as those in the previous example in section 3.2: $a_{\mathrm{M}_{2}}=0.5 \mathrm{~m}, a_{\mathrm{K}_{1}}=0.35 \mathrm{~m}, a_{\mathrm{O}_{1}}=0.2 \mathrm{~m}, \phi_{\mathrm{M}_{2}}=$ $180^{\circ}, \phi_{\mathrm{K}_{1}}=220^{\circ}, \phi_{\mathrm{O}_{1}}=205^{\circ}$; the wave numbers for the principal constituents are given by equation (6). A representative estuarine geometry is $L=10 \mathrm{~km}, L_{A}=3 \mathrm{~km}$, and $C_{d}=0.025$. The four variations of width and depth listed in Table 1 give rise to either flood-dominant or ebb-dominant distortion depending on the parameter $\gamma$.

[30] With just the principal tides $\mathrm{K}_{1}, \mathrm{O}_{1}$, and $\mathrm{M}_{2}$, the duration asymmetry in the tide is ebb-dominant for all of the geometries considered (Figure 5, dashed lines). There is a small phase shift with distance that causes a decrease in the asymmetry of the principal tides. When $\mathrm{M}_{4}$ and $\mathrm{MK}_{3}$ are included (solid lines), the asymmetry changes markedly. Ebb-dominance increases for geometries with $\gamma<0$, while total asymmetry decreases for $\gamma>0$. Flood-dominance does not occur within the solution range (the solutions are only valid up to approximately $x / L=1-L_{A} / L$ ) for the geometries that should be flood-dominant based on $\gamma$ [FA94; Friedrichs and Madsen, 1992].

[31] This simple example demonstrates that estuarine morphology strongly affects tidal asymmetry, as in semidiurnal systems, but that the pre-loading of asymmetry by principal tides must first be overcome in estuaries with mixed semidiurnal/diurnal tides. Thus, asymmetry within an estuary with mixed tides cannot be parameterized solely in terms of principal tides [Hoitink et al., 2003] or overtides [Speer and Aubrey, 1985; Friedrichs and Aubrey, 1988], as there is a spatial dependence to whether the asymmetry created by the principal tides is negated by higher harmonic constituents. In the next section I analyze tidal asymmetry within three California estuaries of differing morphologies to illustrate this point.

\section{Observations From Three California Estuaries}

[32] The tide along the west coast is has a shorter falling water duration, with the asymmetrical tidal forcing strongest along the central California coast (Figure 1d). Duration asymmetry decreases slightly in the Southern California Bight, and is weaker to the north. Three estuaries with different morphologies were selected to examine the estuarine tidal response to this ebb-dominant forcing (Figure 6). Tomales Bay is long and comparatively wide, with little intertidal storage. Elkhorn Slough is long and narrow, with significant intertidal storage and a deep, hardened (jettied) mouth. Oneonta Slough (the north arm of the Tijuana River 
Table 1. Geometric Values Used for Computing Asymmetry in Figure $5^{\mathrm{a}}$

\begin{tabular}{cccc}
\hline $\begin{array}{c}\text { Channel Width, } \\
B(\mathrm{~m})\end{array}$ & $\begin{array}{c}\text { Estuary Width, } \\
b(\mathrm{~m})\end{array}$ & $\begin{array}{c}\text { Depth, } \\
h(\mathrm{~m})\end{array}$ & $\gamma$ (Equation $(7))$ \\
\hline \multirow{4}{*}{ Ebb-Dominant } & \\
100 & 200 & 3 & -0.42 \\
& 200 & 3 & -0.16 \\
& \multicolumn{3}{c}{} \\
100 & Flood-Dominant & \\
100 & 150 & 1.5 & 0.15 \\
& 100 & 1.5 & 0.35 \\
\hline
\end{tabular}

${ }^{\mathrm{a}}$ Here $\gamma$ is calculated from equation (7) with $\alpha=0.5 . L=10 \mathrm{~km}, L_{A}=$ $3 \mathrm{~km}$. See text for details.

estuary) is short and narrow, with a natural beach inlet and moderate intertidal storage. Basin-wide physical characteristics are summarized in Table 2.

[33] Hourly water level observations were obtained from publicly-available data archives for three tide stations within or near each estuary (Table 3 ). Each estuary had a tide station located within one kilometer of the mouth and a second tide station located in the back half of the estuary. The third station was a nearby coastal reference station. General morphologic characteristics were assessed from spatial habitat data delineated by the state of California (i.e., deep-water or intertidal habitat), while depth information was determined from the sources described in Table 2.

[34] In general, the response of the tides in these three estuaries was similar. There was little energy loss in the diurnal and semidiurnal bands between the reference stations and the estuary tide stations, and higher harmonics

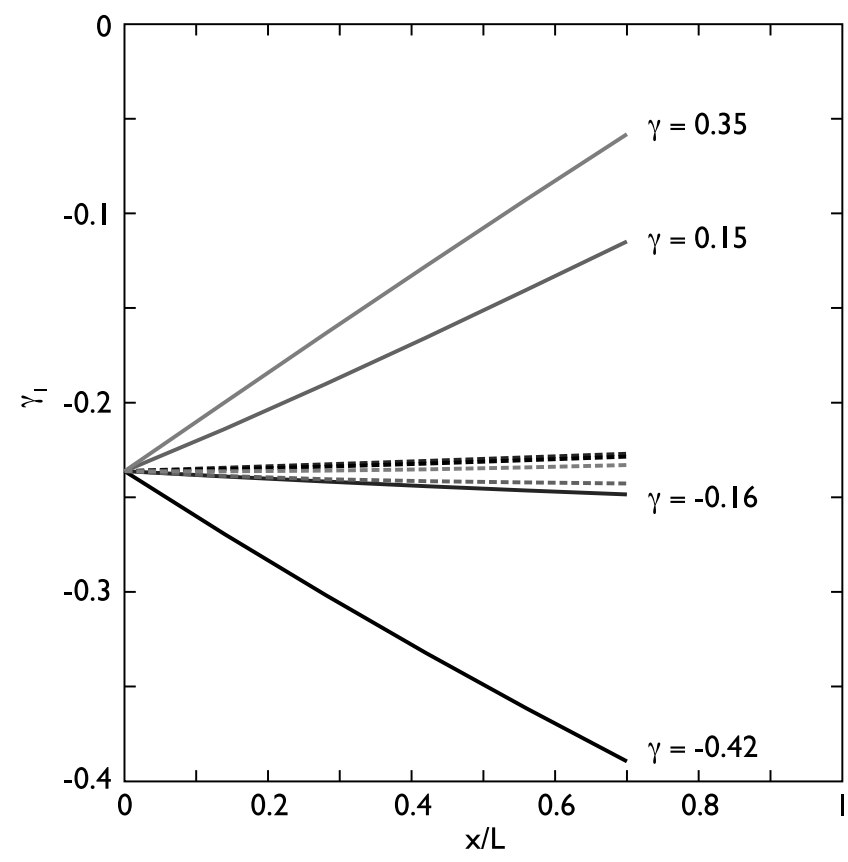

Figure 5. Example of asymmetry for principal tides $\left(\mathrm{K}_{1}+\right.$ $\mathrm{O}_{1}+\mathrm{M}_{2}$, dashed lines) and higher harmonics (principal tides $+\mathrm{M}_{4}+\mathrm{MK}_{3}$, solid lines) for a range of estuarine geometries, listed in Table 1. Asymmetry is quantified as skewness, $\gamma_{1}$ (equation (10)). Amplitudes and phases are the same as those listed in Figure 3. (a) Tomales Bay

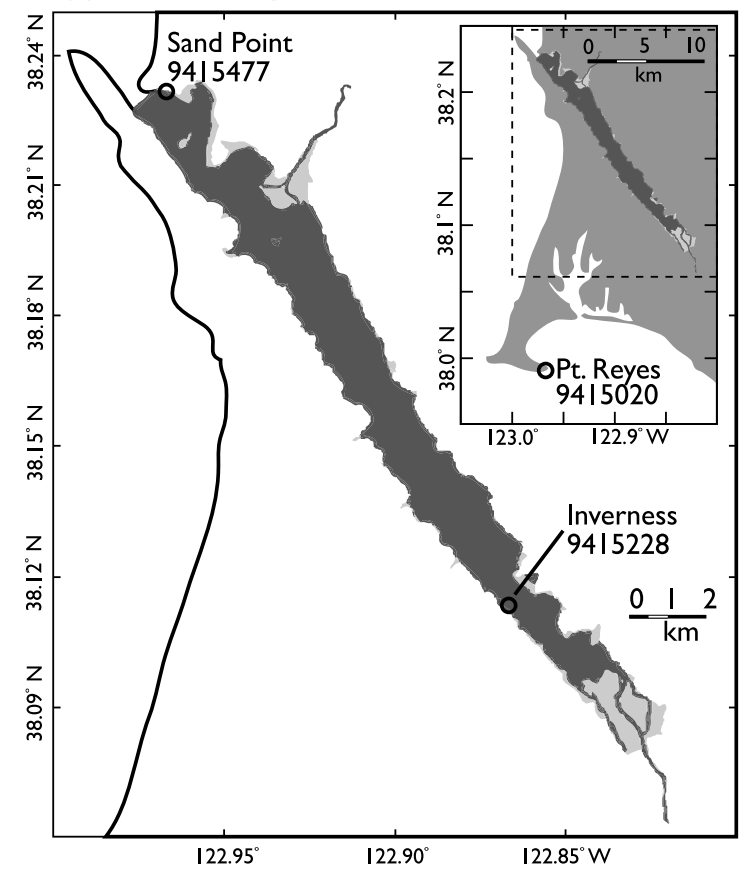

(b) Elkhorn Slough

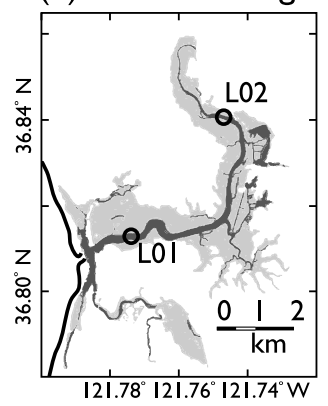

(c) Tijuana River
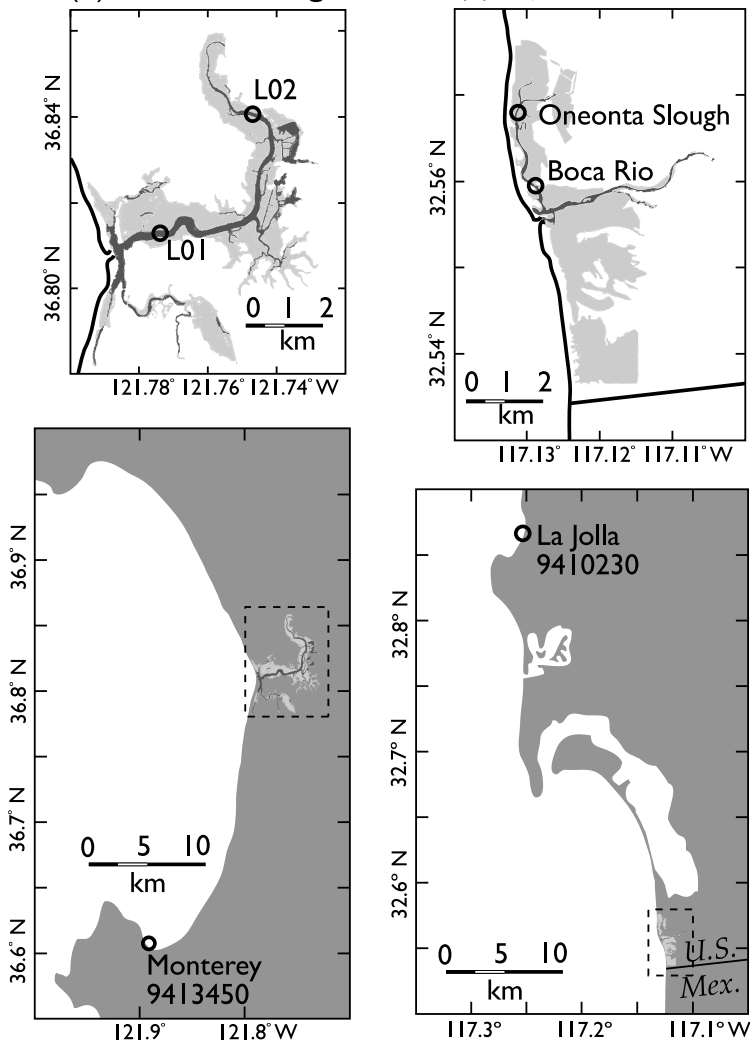

Figure 6. Location of estuary tide observations: (a) Tomales Bay, (b) Elkhorn Slough (main channel), and (c) Tijuana River estuary (North Arm-Oneonta Slough). Estuary tide stations are described in the main text. The coastal maps (with shaded gray coastline) show the location of the reference coastal tide gauge for each estuary (shown boxed). The estuary maps are shaded by deep water (darker is below MLLW) and intertidal (lighter is above MLLW) habitat. 
Table 2. Basin-Scale Morphology for Estuaries Shown in Figure $6^{\mathrm{a}}$

\begin{tabular}{|c|c|c|c|c|c|c|c|c|c|c|c|}
\hline & \multirow[b]{2}{*}{$a(\mathrm{~m})$} & \multicolumn{3}{|c|}{ Estuary } & \multicolumn{3}{|c|}{ Main Channel } & \multicolumn{4}{|c|}{ Inlet } \\
\hline & & $L(\mathrm{~km})$ & $L_{A}(\mathrm{~km})$ & $b(\mathrm{~m})$ & $B(\mathrm{~m})$ & $h(\mathrm{~m})$ & $\gamma$ & $L(\mathrm{~m})$ & $b(\mathrm{~m})$ & $h(\mathrm{~m})$ & $\gamma$ \\
\hline Tomales Bay & 0.9 & 21.1 & 6.3 & 1400 & 1400 & 3 & 0.5 & 2000 & 470 & 2 & 0.7 \\
\hline Elkhorn Slough & 0.8 & 11.1 & 3.6 & 170 & 100 & 3 & -0.1 & 300 & 100 & 5 & 0.2 \\
\hline Tijuana River & 0.8 & 2.7 & 1.1 & 350 & 30 & 1 & 0.4 & 350 & 50 & 1 & 1.2 \\
\hline
\end{tabular}

${ }^{a}$ Length and width estimated from aerial photographs and available literature. Depth in Tomales Bay reported by Hearn and Largier [1997]. Depth in Elkhorn Slough reported by Nidzieko [2009]. Depth in Tijuana River estuary reported by J. Crooks (personal communication, 2009). Coefficient value of $\alpha=0.5$ used for computing $\gamma$ for both inlet and estuary. The amplitude of the tide $a$ is one-half the diurnal range (MHHW - MLLW) reported at each estuary's coastal reference tide station, for the 1983-2001 epoch [National Ocean Service, 2000].

developed only within-estuary (Figures $7 \mathrm{a}-7 \mathrm{c}$ ). Harmonic constituents were computed using the MATLAB program $\mathrm{t}$ tide [Pawlowicz et al., 2002] to obtain amplitude and phase (Figures 7d-7l). All constituents resolvable from their Rayleigh neighbor based on record length [Foreman, 2004] were included in the harmonic analysis, but only selected constituents are reported here. Amplitudes of the principal constituents decreased across the estuary entrances at Tomales Bay and Tijuana River estuary because these two systems have shallow entrances; the strong frictional effects also caused larger phase shifts. Within the estuaries, the relative phasing of the higher harmonics from the lower to upper estuary stations was different for Tomales Bay than for Tijuana River or Elkhorn Slough; the phase shift of $\mathrm{MK}_{3}$ and $\mathrm{M}_{4}$ was negative up-estuary in Tomales Bay, suggesting a different tidal response in this system.

[35] Asymmetry was quantified by computing skewness $\gamma_{1}$ from both observations and a synthetic tidal record created from the amplitudes and phases of the six principal astronomical constituents (Figure 8). Despite the ebb-dominant forcing at the mouth, Tomales Bay and Tijuana estuary were flood-dominant with respect to tidal elevation rise/fall duration in the inner estuary. The changes in asymmetry in the principal tide phasing are not as important as changes in amplitude, based on the different responses of $\gamma_{1}$ and $\mu_{3}$ in Tijuana River Estuary.

\subsection{Tomales Bay}

[36] The observations within Tomales Bay (Figure 6a) are from NOS stations Sand Point (9415477) and Inverness
(9415228), located near the mouth and near the head of the estuary, respectively; the reference location is NOS station Point Reyes (9415020). Tomales Bay is $21 \mathrm{~km}$ long, and $1.4 \mathrm{~km}$ wide. A deeper main channel of $2-10 \mathrm{~m}$ is flanked by shallower $(<2 \mathrm{~m})$ subtidal flats, and intertidal marsh areas are limited to the head of the estuary. Consequently, the width does not change appreciably through the tidal cycle. The laterally averaged depth is $\sim 2$ meters in the first and last five kilometers of the estuary, with a deeper $(\sim 6 \mathrm{~m})$ midsection [Hearn and Largier, 1997]. This geometry engenders flood dominance. Using $\alpha=0.5$ and evaluating $\vec{b}=(b+B) / 2$ for use in equation (7), the morphology asymmetry factor $\gamma=$ $1.5 \frac{0.9}{3}-\frac{1400-1400}{1400}=0.5$. Because of the ebb-dominant tide at the mouth, however, tides in Tomales Bay do not become flood-dominant until beyond the midpoint of the estuary (Figure 8). There is an initial decrease in ebb-dominance that may be associated with the decrease in amplitude of the principal tides across the shallow entrance. The total asymmetry at Inverness is weakly flood-dominant despite a slight increase in ebb-dominance in the principal tides. The phase shift between Sand Point and Inverness for $\mathrm{M}_{4}$ and $\mathrm{MK}_{3}$ is negative, which reflects the flood-dominant morphology. The magnitude of this phase shift is smaller for $\mathrm{MK}_{3}$ than for the principal constituents, which suggests that there are multiple sources of nonlinearity whose phases may partially cancel one another. While many sediment transport mechanisms are at work, it is interesting to consider whether the deeper mid-section of Tomales Bay is due to the apparent sediment transport divergence that may occur with a flooddominant head and ebb-dominant mouth.

Table 3. Tide Stations and Data Sources for Observations ${ }^{\mathrm{a}}$

\begin{tabular}{|c|c|c|c|c|}
\hline Station Name & Latitude & Longitude & Period of Record & Source \\
\hline \multicolumn{5}{|c|}{ Tomales Bay } \\
\hline Point Reyes (9415020) & $37^{\circ} 59.8^{\prime} \mathrm{N}$ & $122^{\circ} 58.6^{\prime} \mathrm{W}$ & 24 Sep 1993 to 17 Feb 1994 & NOS \\
\hline Sand Point (9415477) & $38^{\circ} 13.9^{\prime} \mathrm{N}$ & $122^{\circ} 58.0^{\prime} \mathrm{W}$ & 24 Sep 1993 to 17 Feb 1994 & NOS \\
\hline Inverness (9415228) & $38^{\circ} 6.8^{\prime} \mathrm{N}$ & $122^{\circ} 52.0^{\prime} \mathrm{W}$ & 24 Sep 1993 to 17 Feb 1994 & NOS \\
\hline \multicolumn{5}{|c|}{ Elkhorn Slough } \\
\hline Monterey (9413450) & $36^{\circ} 36.3^{\prime} \mathrm{N}$ & $121^{\circ} 53.3^{\prime} \mathrm{W}$ & 1 Jan 2006 to $2 \operatorname{Jan} 2007$ & NOS \\
\hline Seal Bend (L01) & $36^{\circ} 48.7^{\prime} \mathrm{N}$ & $121^{\circ} 46.5^{\prime} \mathrm{W}$ & 1 Jan 2006 to $2 \operatorname{Jan} 2007$ & LOBO \\
\hline Kirby Park (L02) & $36^{\circ} 50.5^{\prime} \mathrm{N}$ & $121^{\circ} 51.9^{\prime} \mathrm{W}$ & 1 Jan 2006 to 2 Jan 2007 & LOBO \\
\hline \multicolumn{5}{|c|}{ Tijuana River Estuary } \\
\hline La Jolla (9410230) & $32^{\circ} 52.0^{\prime} \mathrm{N}$ & $117^{\circ} 15.5^{\prime} \mathrm{W}$ & 1 Jan 2007 to 31 Dec 2007 & NOS \\
\hline Boca Rio (tjrbrwq) & $32^{\circ} 33.6^{\prime} \mathrm{N}$ & $117^{\circ} 7.7^{\prime} \mathrm{W}$ & 1 Jan 2007 to 31 Dec 2007 & TJNERR \\
\hline Oneonta Slough (tjroswq) & $32^{\circ} 34.1^{\prime} \mathrm{N}$ & $117^{\circ} 7.9^{\prime} \mathrm{W}$ & 1 Jan 2007 to 31 Dec 2007 & TJNERR \\
\hline
\end{tabular}

${ }^{\mathrm{a}}$ National Ocean Service (NOS) tide data was obtained from the Center for Operational Oceanographic Products and Services (http:// tidesandcurrents.noaa.gov/). Land/Ocean Biogeochemical Observatory (LOBO) data was obtained from Monterey Bay Aquarium Research Institute (http://www.mbari.org/). Tijuana River National Estuarine Research Reserve (TJNERR) System-Wide Monitoring Program data was obtained from the National Estuarine Research Reserve System Centralized Data Management Office (http:// cdmo.baruch.sc.edu/). 


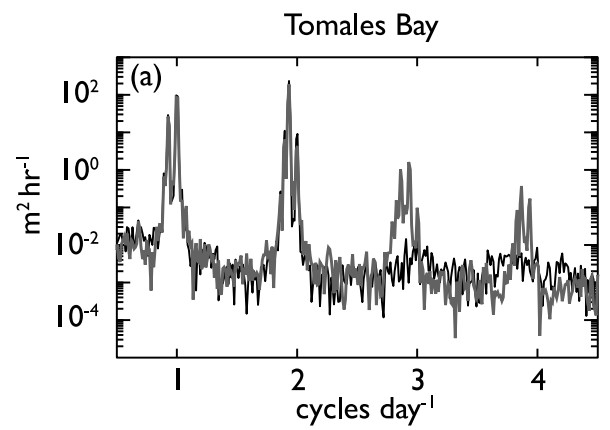

(d)
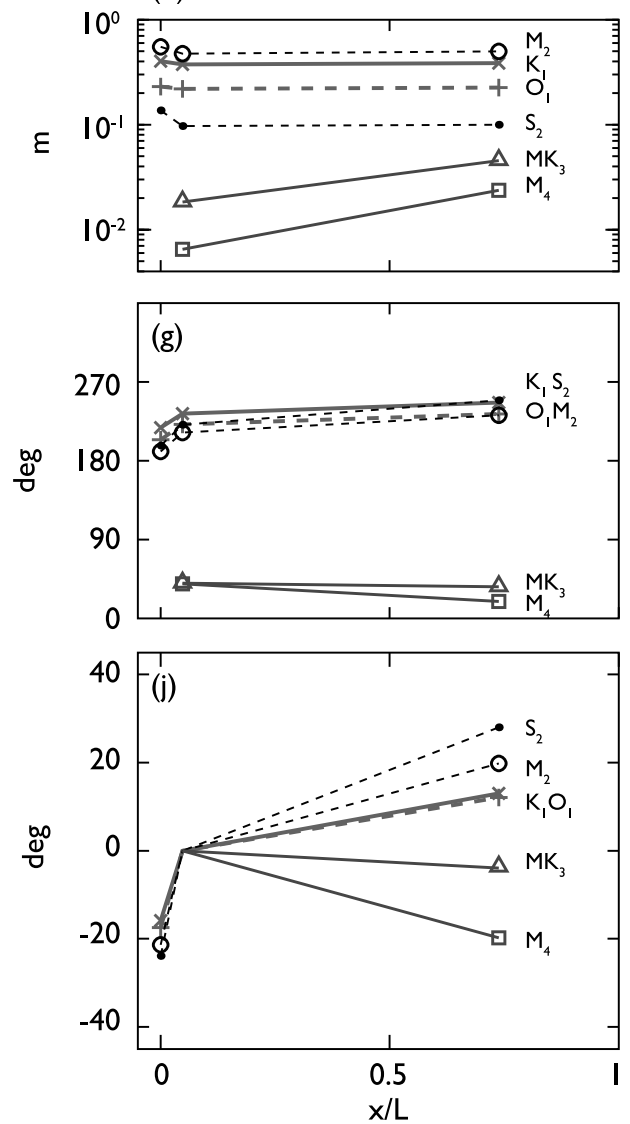

Elkhorn Slough

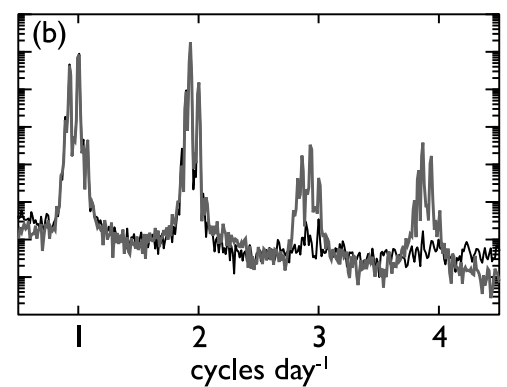

(e)
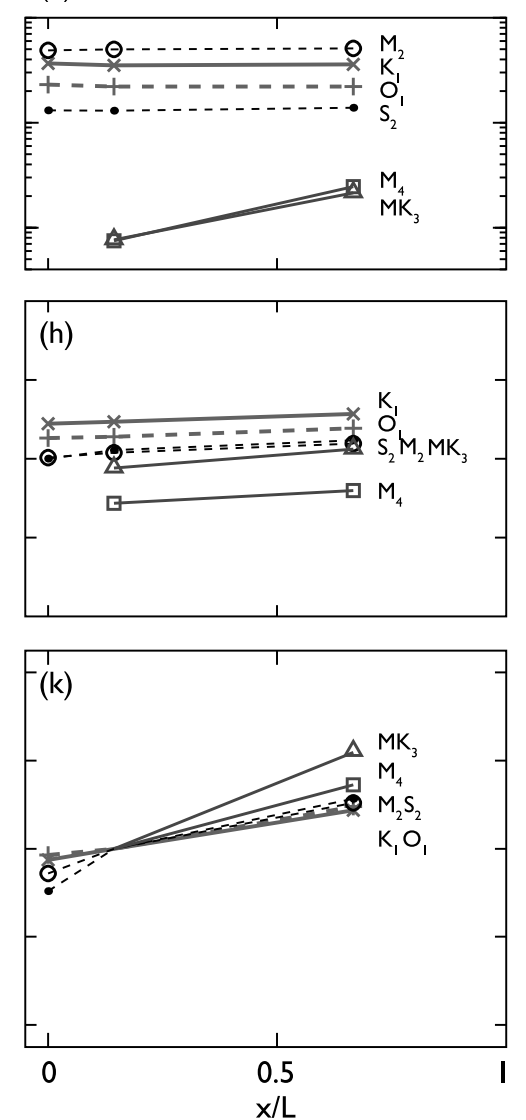

Tijuana River Estuary

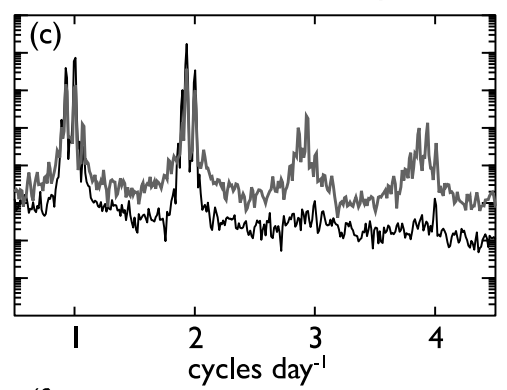

(f)
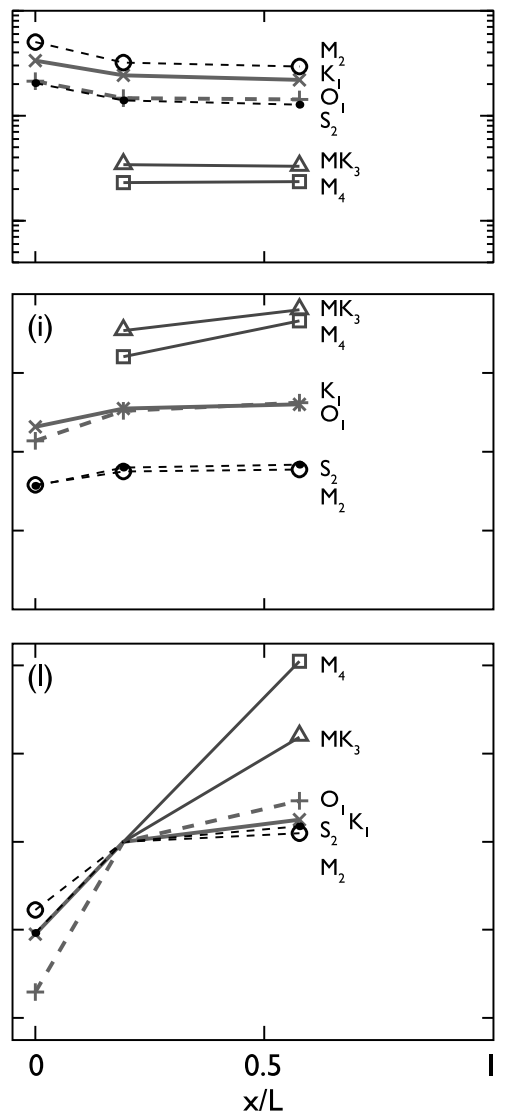

Figure 7. $(\mathrm{a}-\mathrm{c})$ Power spectral density plots for each reference tide station (black) and the most landward estuary observation station (gray) for the systems shown in Figure 6. (d-f) Tidal elevation amplitude growth for selected constituents. (g-i) Phase shift for selected constituents. (j-1) Phase shift normalized to observations at each seaward estuary tide station.

\subsection{Elkhorn Slough}

[37] The observations within Elkhorn Slough (Figure 6b) are from Land/Ocean Biogeochemical Observatory nodes L01 (near Seal Bend) and L02 (near Kirby Park), at the mouth and head respectively; the reference location is NOS station Monterey (9413450). Tidal scour and dredging maintain a deep ( $>4 \mathrm{~m}$ ) entrance to Elkhorn Slough that is constrained by a bridge and a pair of jetties that extend nearly to the head of the Monterey Submarine Canyon. Consequently, there is no amplitude loss across the entrance and the principal tide phase lag between Monterey and L01 is smaller than in the other two estuaries. Elkhorn Slough is $11 \mathrm{~km}$ long, with a narrow main channel $(100 \mathrm{~m})$ flanked by wide $(270 \mathrm{~m})$ intertidal marsh. The mean depth of the main channel is $3 \mathrm{~m}$. This morphology is ebb-dominant $\gamma=$ $1.5 \frac{0.8}{3}-\frac{185-100}{185}=-0.1$, and the higher harmonics reinforce the ebb-dominance of the principal tides. The net effect of this ebb-dominance has been a widening and deepening of the main channel that is well-documented [Malzone, 1999; Dean, 2003].

\subsection{Tijuana River Estuary}

[38] The observations within Tijuana River estuary (Figure 6c) are from the Tijuana River Estuary National Estuarine Research Reserve System-wide Monitoring Program stations Boca Rio and Oneonta Slough, near the mouth and up-estuary, respectively; the reference location is NOS station La Jolla (9410230). Station San Diego (9410170) is 
(a) skewness (normalized third moment)

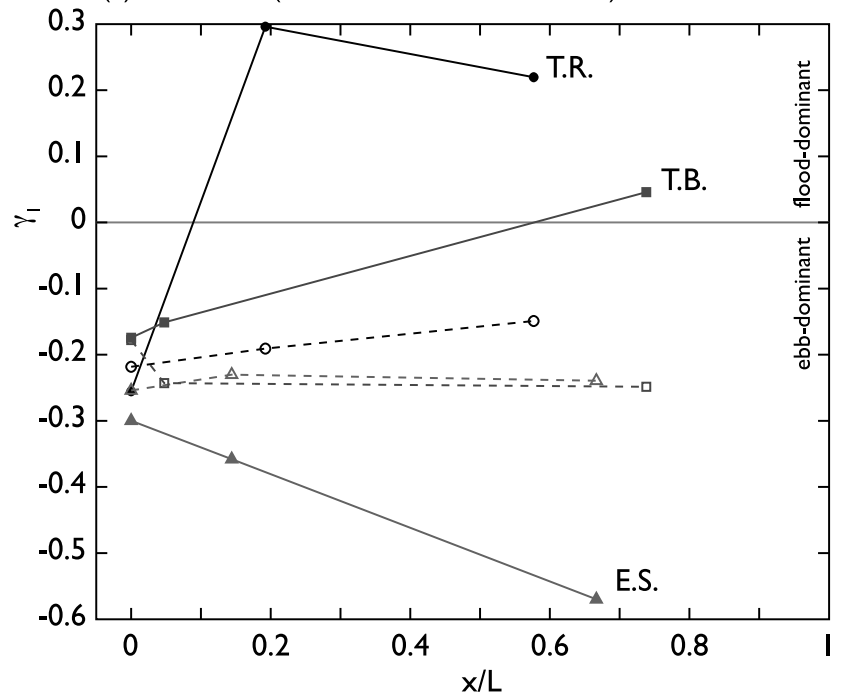

(b) third moment

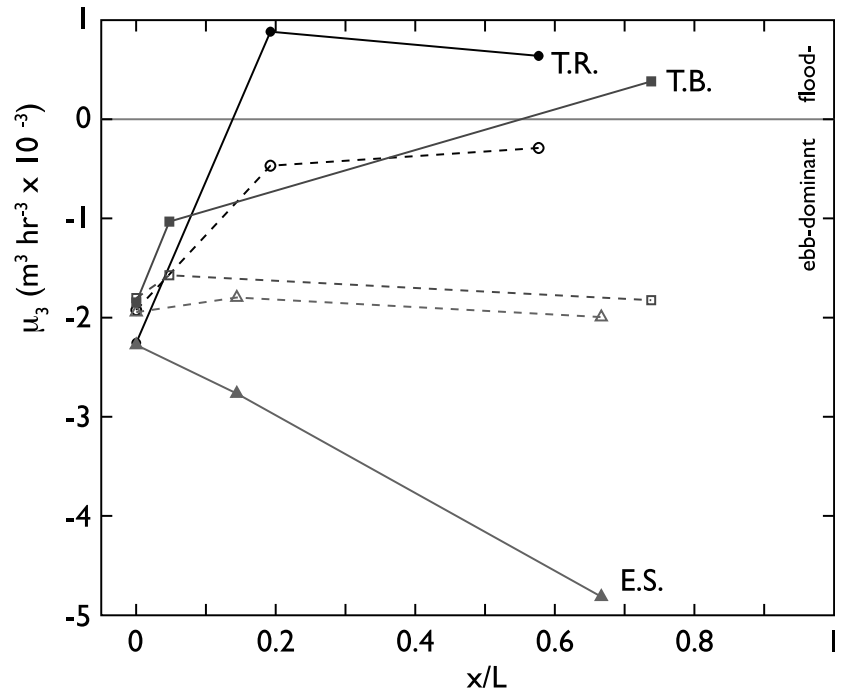

Figure 8. Asymmetry as function of distance along-channel for Tomales Bay (squares), Elkhorn Slough (triangles), and Tijuana River Estuary (circles). Asymmetry was computed from observations (solid symbols, solid lines) and from a record constructed from the constituents K1, O1, and M2 derived from harmonic analyses (open symbols, dashed lines). (a) Skewness and (b) third sample moment about the mean.

closer, but located within San Diego Bay, and therefore does not provide an ideal reference as the tidal signal there contains shallow water constituents. Oneonta Slough (the north arm of the Tijuana River estuary) is the smallest of the three estuaries considered here; it is $2.7 \mathrm{~km}$ long, with a shallow $(\sim 1 \mathrm{~m})$, narrow $(30 \mathrm{~m})$ channel. The intertidal marsh width is $350 \mathrm{~m}$ wide. The shallow, perched beach entrance of the Tijuana River estuary causes a large amplitude decrease and phase shift that creates flood-dominance immediately inside the estuary [Lincoln and FitzGerald, 1988; Speer et al., 1991]. Despite the wide intertidal areas in Oneonta Slough, however, the shallow channel engenders flood-dominance $\gamma=1.5 \frac{0.8}{1}-\frac{190-30}{190}=0.4$. The infilling of the main channel and inlet mouth with littoral sediments has been documented at this location [Jenkins and Wasyl, 2005], and is a concern for the success of restoration activities.

\section{Conclusions}

[39] In estuaries with mixed, mainly semidiurnal tides, tidal asymmetry arises from the interaction of both the principal tides and higher harmonics. The asymmetry caused by the principal tides (e.g., $\mathrm{K}_{1}, \mathrm{O}_{1}$, and $\mathrm{M}_{2}$ ) on the west coast of the continental United States is ebb-dominant with respect to duration asymmetry, and so the tide entering estuaries is also ebb-dominant, prior to any internal distortions within the estuary. I have quantified the asymmetry in terms of the sample skewness, $\gamma_{1}$, the normalized third sample moment. Tidal elevation asymmetry can be quantified by taking the time-derivative of a tidal elevation time record, while tidal current asymmetry can be quantified directly from a velocity time series. Assuming tidal elevation and velocity to be in quadrature, the tide is ebb-dominant for $\gamma_{1}<0$ and flood-dominant for $\gamma_{1}>0$ in the absence of additional factors such as mean river flow, stratification, and bathymetric effects. An analytic approximation to the skewness shows that the traditional metrics of asymmetry, namely the ratio of constituent amplitudes and the relative constituent phase difference, arise from calculating the third sample moment.

[40] Observations of water level from three California estuaries of different morphologies were analyzed via harmonic analysis, and duration asymmetry was quantified via the skewness. Despite the ebb-dominant tide at their mouth, two of the estuaries became flood-dominant. Tijuana River estuary becomes flood-dominant because of its shallow beach entrance and channel, while Tomales Bay becomes flood-dominant in its upper reaches as the estuary shoals. Elkhorn Slough, by contrast, has significant intertidal storage and a deep entrance and main channel, and becomes more ebb-dominant with the addition of nonlinear distortions. These observations and the analytic arguments indicate that the principal tides are equally important to the total asymmetry within these estuaries. The differential phase shift of the principal tides within the estuary contributes little to internal changes in asymmetry compared to the significant growth of higher harmonics, most notably $\mathrm{M}_{4}$ and $\mathrm{MK}_{3}$. The morphology of an estuary (parameterized by the relative importance of depth and width changes with tidal elevation) is a good predictor of whether higher harmonics engender ebb-dominance or flood-dominance in these systems, although the asymmetry imposed by the principal tides at the mouth must first be overcome. This spatial evolution in the total asymmetry suggests that quantifying observations via skewness should be preferred over traditional metrics in estuaries with mixed tides.

[41] Acknowledgments. I would like to thank S. G. Monismith for reading and commenting on the manuscript, and for his encouragement. Support for the writing and publication of the manuscript was provided via the Stanford Singapore Partnership while I was a Guest Investigator with D. Ralston at Woods Hole Oceanographic Institution, and by 
USGS/WHOI Postdoctoral Scholar funds. Conversations with R. Geyer, who suggested the fortnightly de-correlation timescale as an upper bound on window length, were helpful. The comments of two anonymous reviewers are appreciated. Maria Little at NOAA provided unpublished tide records at Inverness, Sand Point, and La Jolla. Martha Sutula and Becky Schaffner at Southern California Coastal Water Research Project provided the wetland delination data. I am particularly grateful to the many unnamed personnel involved with the collection of observations at NOAA (Tomales Bay and coastal reference stations), MBARI (Elkhorn Slough LOBO), and the TRNERR (Tijuana River estuary SWMP stations).

\section{References}

Aubrey, D. G., and P. E. Speer (1985), A study of non-linear tidal propagation in shallow inlet estuarine systems. Part 2. Observations, Estuarine Coastal Shelf Sci., 21(2), 185-205.

Bagnold, R. A. (1966), An Approach to the Sediment Transport Problem From General Physics, U.S. Gov. Print. Off., Washington, D. C.

Blanton, J. O., G. Q. Lin, and S. A. Elston (2002), Tidal current asymmetry in shallow estuaries and tidal creeks, Cont. Shelf Res., 22(11-13), 17311743.

Boon, J. D., and R. J. Byrne (1981), On basin hypsometry and the morphodynamic response of coastal inlet systems, Mar. Geol., 40(1-2), 27-48.

Dean, E. W. (2003), Tidal scour in Elkhorn Slough, California: A bathymetric analysis, M.Sc. thesis, Inst. of Earth Syst. Sci. and Policy, Calif. State Univ., Monterey Bay, Calif.

Doodson, A. T. (1921), The harmonic development of the tide-generating potential, Proc. R. Soc. London A, 100(704), 305-329.

Dronkers, J. (1986), Tidal asymmetry and estuarine morphology, Neth. J. Sea Res., 20(2-3), 117-131.

Dworak, J. A., and J. Gomez-Valdes (2005), Modulation of shallow water tides in an inlet-basin system with a mixed tidal regime, J. Geophys. Res., 110, C01007, doi:10.1029/2003JC001865.

Emery, W. J., and R. E. Thomson (2001), Data Analysis Methods in Physical Oceanography, 2nd ed., Elsevier, Amsterdam.

Foreman, M. G. G. (2004), Manual for tidal heights analysis and prediction, Pac. Mar. Sci. Rep. 77-10, Inst. of Ocean Sci., Victoria, B. C., Canada

Friedrichs, C. (1995), Stability shear stress and equilibrium cross-sectional geometry of sheltered tidal channels, J. Coastal Res., 11, 1062-1074.

Friedrichs, C. T., and D. G. Aubrey (1988), Non-linear tidal distortion in shallow well-mixed estuaries: A synthesis, Estuarine Coastal Shelf Sci., 27(5), 521-545.

Friedrichs, C. T., and D. G. Aubrey (1994), Tidal propagation in strongly convergent channels, J. Geophys. Res., 99(C2), 3321-3336.

Friedrichs, C. T., and O. S. Madsen (1992), Nonlinear diffusion of the tidal signal in frictionally dominated embayments, J. Geophys. Res., 97(C4), $5637-5650$.

Godin, G. (1985), Modification of river's tides by its discharge, J. Waterw. Port Coastal Ocean Eng., 111(2), 257-274.

Godin, G. (1991), The analysis of tides and currents (review), in Tidal Hydrodyn., edited by B. B. Parker, pp. 675-708, John Wiley, New York.

Godin, G., and I. Gonzalez (1991), About some very small harmonics which are present in the tide of the Pacific, Dtsch. Hydrogr. Z., 44(3), $115-132$.

Godin, G., and A. Martínez (1994), Numerical experiments to investigate the effects of quadratic friction on the propagation of tides in a channel, Cont. Shelf Res., 14(7), 723-748.

Hearn, C. J., and J. L. Largier (1997), The summer buoyancy dynamics of a shallow Mediterranean estuary and some effects of changing bathymetry: Tomales Bay, California, Estuarine Coastal Shelf Sci., 45(4), 497-506.

Heath, R. (1980), Phase relations between the over- and fundamental-tides, Dtsch. Hydrogr. Z., 33(5), 177-191, doi:10.1007/BF02226319.

Hoitink, A. J. F., P. Hoekstra, and D. S. van Maren (2003), Flow asymmetry associated with astronomical tides: Implications for the residual transport of sediment, J. Geophys. Res., 108(C10), 3315, doi:10.1029/2002JC001539.

Inoue, R., and C. Garrett (2007), Fourier representation of quadratic friction, J. Phys. Oceanogr., 37(3), 593-610.
Jay, D. A. (1991), Green's Law revisited: Tidal long-wave propagation in channels with strong topography, J. Geophys. Res., 96(C11), 20,585-20,598.

Jenkins, S. A., and J. Wasyl (2005), Analysis of coastal processes effects due to the Tijuana Estuary restoration project, technical report, Dr. Scott A. Jenkins Consult., Poway, Calif.

Lanzoni, S., and G. Seminara (1998), On tide propagation in convergent estuaries, J. Geophys. Res., 103(C13), 30,793-30,812.

Largier, J. L., J. T. Hollibaugh, and S. V. Smith (1997), Seasonally hypersaline estuaries in Mediterranean-climate regions, Estuarine Coastal Shelf Sci., 45(6), 789-797.

LeBlond, P. H. (1978), On tidal propagation in shallow rivers, J. Geophys. Res., 83(C9), 4717-4721.

Lincoln, J., and D. FitzGerald (1988), Tidal distortions and flood dominance at five small tidal inlets in southern Maine, Mar. Geol., 82(3-4), 133-148.

Malzone, C. (1999), Tidal scour and its relation to erosion and sediment transport in Elkhorn Slough, M.Sc. thesis, Dep. of Geol., San Jose State Univ., San Jose, Calif.

National Ocean Service (2000), Tide and Current Glossary, NOAA, Silver Spring, Md.

Nidzieko, N. J. (2009), Dynamics of a seasonally low-inflow estuary: Circulation and dispersion in Elkhorn Slough, California, Ph.D. thesis, Stanford Univ., Stanford, Calif.

Parker, B. B. (1991), The relative importance of the various nonlinear meachanisms in a wide range of tidal interactions (review), in Tidal Hydrodynamics, edited by B. B. Parker, pp. 237-268, John Wiley, New York.

Pawlowicz, R., B. Beardsley, and S. Lentz (2002), Classical tidal harmonic analysis including error estimates in MATLAB using T-TIDE, Comput. Geosci., 28(8), 929-937.

Pingree, R. D. (1983), Spring tides and quadratic friction, Deep Sea Res. Part A, 30(9), 929-944.

Pingree, R. D., and D. K. Griffiths (1987), Tidal friction for semidiurnal tides, Cont. Shelf Res., 7(10), 1181-1209.

Prandle, D. (2003), Relationships between tidal dynamics and bathymetry in strongly convergent estuaries, J. Phys. Oceanogr., 33(12), 2738-2750. Prandle, D., and M. Rahman (1980), Tidal response in estuaries, J. Phys. Oceanogr., 10(10), 1552-1573.

Ranasinghe, R., and C. Pattiaratchi (2000), Tidal inlet velocity asymmetry in diurnal regimes, Cont. Shelf Res., 20(17), 2347-2366.

Savenije, H. H. G., and E. J. M. Veling (2005), Relation between tidal damping and wave celerity in estuaries, J. Geophys. Res., 110, C04007, doi:10.1029/2004JC002278.

Savenije, H. H. G., M. Toffolon, J. Haas, and E. J. M. Veling (2008), Analytical description of tidal dynamics in convergent estuaries, J. Geophys. Res., 113, C10025, doi:10.1029/2007JC004408.

Speer, P. E., and D. G. Aubrey (1985), A study of non-linear tidal propagation in shallow inlet estuarine systems. Part 2. Theory, Estuarine Coastal Shelf Sci., 21(2), 207-224.

Speer, P. E., D. G. Aubrey, and C. T. Friedrichs (1991), Nonlinear hydrodynamics of shallow tidal inlet/bay systems, in Tidal Hydrodynamics, edited by B. B. Parker, pp. 321-339, John Wiley, New York.

van de Kreeke, J., and K. Robaczemska (1993), Tide-induced residual transport of coarse sediment: Application to the Ems Estuary, Neth. J. Sea Res., 31(3), 209-220.

Wang, Z. B., M. C. J. L. Jeuken, and H. J. de Vriend (1999), Tidal asymmetry and residual sediment transport in estuaries, Technical Report Z2749, WL Delft Hydraul., Delft, Netherlands.

Woodworth, P. L., D. L. Blackman, D. T. Pugh, and J. M. Vassie (2005), On the role of diurnal tides in contributing to asymmetries in tidal probability distribution functions in areas of predominantly semi-diurnal tide, Estuarine Coastal Shelf Sci., 64(2-3), 235-240.

N. J. Nidzieko, Applied Ocean Physics and Engineering Department, Woods Hole Oceanographic Institution, 266 Woods Hole Rd., Woods Hole, MA 02543, USA. (nidzieko@whoi.edu) 